\title{
Organometallic Glutathione S-Transferase Inhibitors
}

\author{
Emilia Păunescu, ${ }^{* \dagger}$ Mylène Soudani, ${ }^{\dagger}$ Paloma Martin, ${ }^{\ddagger}$ Rosario Scopelliti, ${ }^{\dagger}$ Mario Lo Bello, ${ }^{\ddagger}, \perp$ \\ and Paul J. Dyson*, ${ }^{\dagger}$ \\ ${ }^{\dagger}$ Institut des Sciences et Ingénierie Chimiques, Ecole Polytechnique Fédérale de Lausanne (EPFL), CH-1015 Lausanne, Switzerland \\ "Department of Biology, University of Rome "Tor Vergata”, Via della Ricerca Scientifica 1, 00133 Rome, Italy
}

\section{Supporting Information}

\begin{abstract}
A new family of organometallic $p$-cymene ruthenium(II) and osmium(II) complexes conjugated to ethacrynic acid, a glutathione transferase (GST) inhibitor, is reported. The ethacrynic acid moiety (either one or two) is tethered to the arene ruthenium(II) and osmium(II) fragments via strongly coordinating modified bipyridine ligands. The solid-state structure of one of the complexes, i.e. $\left[\mathrm{Os}\left(\eta^{6}-p\right.\right.$-cymene $\left.) \mathrm{Cl}\right]\left[\left(4^{\prime}\right.\right.$-methyl-[2,2'-bipyridin $]-4$-yl $)$ methyl-2-(2,3-dichloro-4-(2-methylenebutanoyl)phenoxy)acetate] $\mathrm{Cl}$, was established by single-crystal X-ray diffraction, corroborating the expected structure. The complexes are efficient inhibitors of GST P1-1, an enzyme expressed in cancer cells and implicated in drug resistance, and are cytotoxic to the GST-overexpressing chemoresistant A2780cisR ovarian cancer cell line.
\end{abstract}

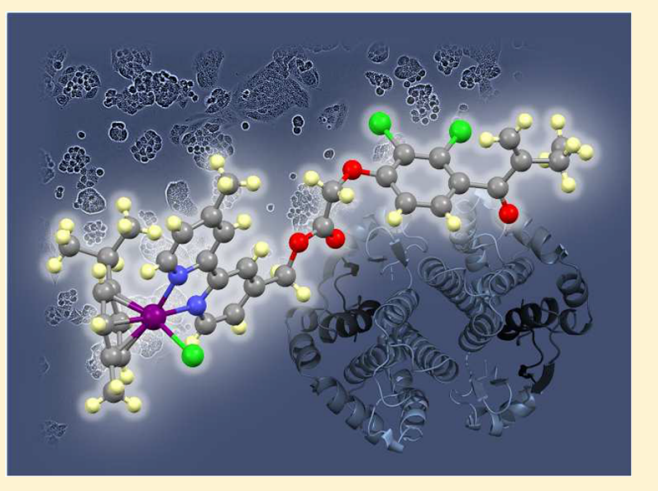

\section{INTRODUCTION}

Resistance to chemotherapy, either intrinsic or acquired, remains a serious obstacle in cancer treatment. Drug resistance is a multifactorial process, and several basic mechanisms have been identified, including enhanced drug efflux associated with the P-glycoprotein, enhanced repair of drug-induced injury, and enhanced detoxification of drug intermediates, frequently related to intracellular glutathione (GSH) and GSH-associated enzymes. ${ }^{1-4}$ In particular, the overexpression of glutathione transferases (GSTs) and efflux pumps in cancer cells reduces the efficacy of various anticancer drugs, ${ }^{1-4}$ and the search for compounds capable of inhibiting GSTs and/or efflux pumps is key to overcoming resistance to anticancer drugs.

GSTs are a family of homo- and heterodimeric cytosolic enzymes that catalyze the conjugation of GSH with a variety of exogenous and endogenous electrophiles and, consequently, are involved in the inactivation of various electrophile-producing anticancer agents. The products, in the form of mercapturates, are subsequently eliminated from the cell. ${ }^{5}$ As GSH and the GST superfamily play an important role in the mechanism of anticancer drug resistance, ${ }^{2,6-8}$ including metal-based drugs, $^{9-15}$ efforts have focused on the development of GST inhibitors and GST-activated prodrugs as means of sensitizing drug-resistant cancer cells to treatment. ${ }^{16-18}$ In this context, ethacrynic acid ([2,3-dichloro-4-(2-methylene-1-oxobutyl)phenoxyl]acetic acid, EA-H; Figure 1) is a versatile, watersoluble compound that modulates GST activity. EA-H conjugation to GSH may occur in a spontaneous fashion or via the catalytic action of the major classes of GST $(\alpha, \mu$, and $\pi$ ), with the $\pi$ isozyme being the most active. ${ }^{19}$ EA-H potentiates the in vitro cytotoxicity of chemotherapeutic agents, including alkylating agents such as melfalan, ${ }^{20-23}$ carmustine, ${ }^{24}$ mitomycin C, ${ }^{25}$ nitrogen mustards, ${ }^{17,26}$ and chlorambucil. ${ }^{19,27}$ EA-H induced sensitization of tumor cells to doxorubicin ${ }^{26,28}$ or cisplatin ${ }^{20,29,30}$ has also been reported. It was suggested that EA-H may modulate the drug resistance of tumor cells not only by inhibiting GST activity but also by inhibiting the export of GSH conjugates of drugs from the cell by the multidrug resistance protein. ${ }^{31}$

Platinum-based cancer drugs, such as cisplatin, are highly effective chemotherapeutic agents used extensively for the treatment of solid tumors. Nevertheless, drug resistance is a major obstacle for platinum-based chemotherapy, frequently attributed to GSH-mediated detoxification. GST enzymes, specifically GST- $\pi$ isozymes, are overexpressed in cisplatinresistant cell lines, and the inhibition of these enzymes can lead to the reversal of drug resistance, as the combination of cisplatin with EA-H resulted in improved activity against

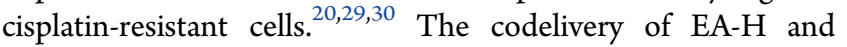
DACHPt (a precursor of oxaliplatin) using biodegradable nanoparticles results in an enhancement of the anticancer efficacy. ${ }^{32}$ In vivo, the nanoparticles demonstrated greater anticancer efficacy and less systemic toxicity, in comparison to a combination therapy involving the free drugs. ${ }^{32}$ Recently, GST inhibitor-anticancer drug conjugates have been reported, such as ethacraplatin, a platinum(IV) metallodrug with two tethered EA-H moieties. ${ }^{33-35}$ Ethacraplatin is a stronger inhibitor of GST activity in live mammalian cells in comparison to either cisplatin or EA-H alone, ${ }^{33}$ and the complex was shown to reverse cisplatin resistance in the microsomal-GST-over-

Received: June 20, 2017

Published: August 24, 2017 
<smiles>C=C(CC)C(=O)c1ccc(OCC(=O)O)c(Cl)c1Cl</smiles>

EA-H

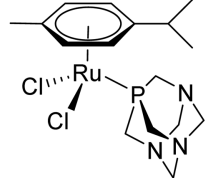

RAPTA-C

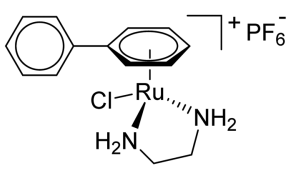

RM175
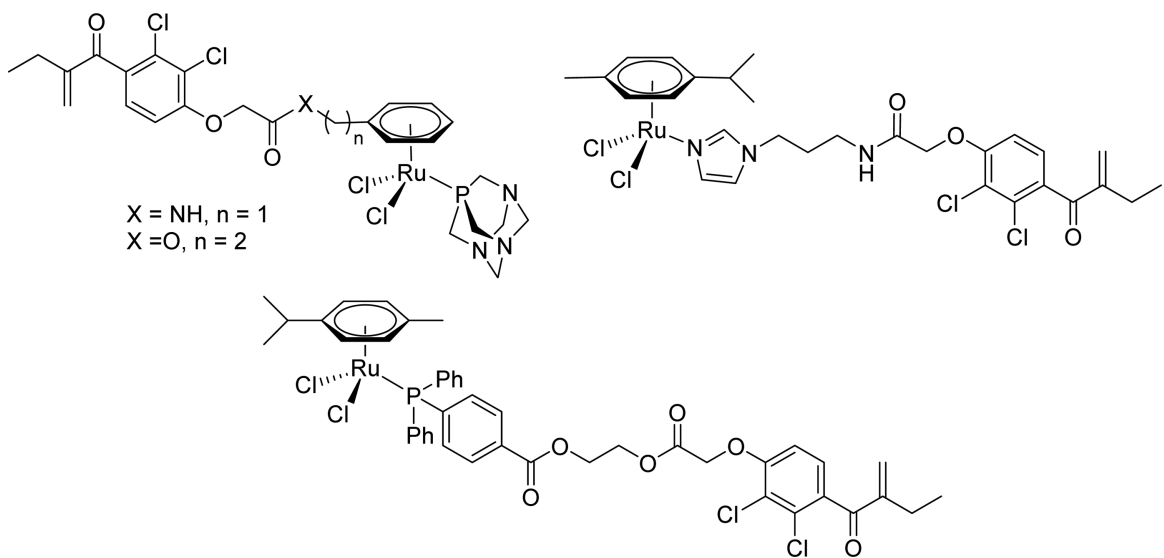

Figure 1. Structure of ethacrynic acid (EA-H), RAPTA-C, RM175, and examples of ethacrynic acid-ruthenium(II) conjugates.

expressing MCF7 cell line. ${ }^{36}$ Platinum(II)-EA conjugates have been also reported. ${ }^{34}$

Ruthenium compounds are promising alternatives to classical platinum-based derivatives, and various ruthenium(III) and ruthenium(II) complexes have been reported to exhibit relevant antitumor activity. Two octahedral ruthenium(III) complexes are under clinical development: i.e., trans-[HIm]$\left[\mathrm{Ru}^{\mathrm{III}} \mathrm{Cl}_{4}(\mathrm{DMSO})(\mathrm{Im})\right](\mathrm{Im}=$ imidazole; NAMI-A), which is essentially inactive on primary tumors but exhibits antimetastatic activity, ${ }^{37-39}$ and trans- $[\mathrm{HIn}]\left[\mathrm{Ru}^{\mathrm{III}} \mathrm{Cl}_{4}(\mathrm{Ind})_{2}\right]$ (Ind = indazole; KP1019), which is active against primary tumors. ${ }^{40,41}$ Organometallic ruthenium(II) arene complexes such as $\left[\mathrm{Ru}^{\mathrm{II}}\left(\eta^{6}\right.\right.$ - $p$-cymene)(PTA) $\left.\mathrm{Cl}_{2}\right]$ (PTA $=1,3,5$-triaza-7phosphatricyclo[3.3.1.1] decane; RAPTA-C $)^{42-45}$ and $\left[\mathrm{Ru}^{\mathrm{II}}\left(\eta^{6} \text { - } p \text {-cymene }\right)(\mathrm{en}) \mathrm{Cl}\right]^{+}(\mathrm{en}=$ ethylenediamine; RM175) ${ }^{46-48}$ (Figure 1) show considerable promise as anticancer drugs in a number of preclinical models. Osmium(II)-based analogues of these compounds have also been reported and show promising anticancer properties. ${ }^{48,49}$

One strategy used to modulate the medicinal properties of ruthenium(II) arene complexes (and related osmium compounds) is to tether a functional bioactive molecule to the metal framework. ${ }^{50-57}$

Since bifunctional RAPTA-like compounds modified with EA show promise as both GST inhibitors and anticancer agents (Figure 1),,$^{33,58-62}$ we decided to prepare and evaluate a new generation of dual-targeting ruthenium(II) - and osmium(II)EA conjugates related to the $\left[\mathrm{Ru}^{\mathrm{II}}\left(\eta^{6}-p \text {-cymene }\right)(\mathrm{en}) \mathrm{Cl}\right]^{+}$ structural motif, in which the en ligand is replaced by EAmodified bipyridine ligands.

\section{RESULTS AND DISCUSSION}

The compounds described in this study were prepared according to the routes shown in Schemes 1 and 2. Bipyridine derivatives were modified with either one or two EA units (it has been shown that organic compounds containing two EA units are potent inhibitors of $\mathrm{GST}^{63,64}$ ). The route to the bipyridine ligand with one EA moiety, i.e. L1, involves the direct reaction of EA-H with 4-hydroxymethyl-4'-methyl-2,2'-
Scheme 1. Synthesis of Ligand L1 and Complexes 1a,b<smiles>C=C(C[CH2+])C(=O)c1ccc(OCC(=O)O)c(Cl)c1Cl</smiles><smiles>C=C(CC)C(=O)c1ccc(OCC(=O)OCc2ccnc(-c3cc(C)ccn3)c2)c(Cl)c1Cl</smiles>

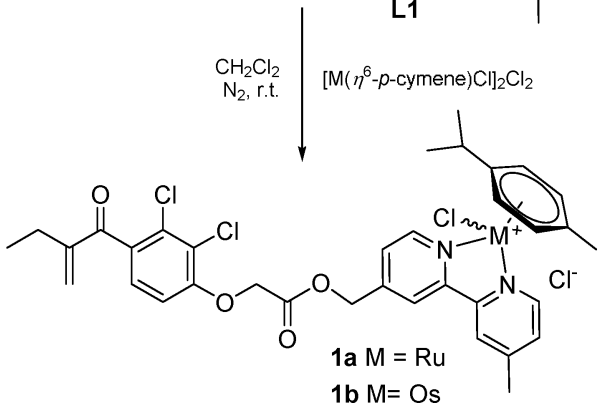

bipyridyl in the presence of 1-ethyl-3-(3-(dimethylamino)propyl)carbodiimide (EDCI) employed as a coupling agent and 4-(dimethylamino)pyridine (DMAP) catalyst. Subsequent reaction of $\mathbf{L 1}$ with the dimers $\left[\mathrm{M}\left(\eta^{6}-p\right.\right.$-cymene $) \mathrm{Cl}_{2} \mathrm{Cl}_{2}(\mathrm{M}$ $=\mathrm{Ru}, \mathrm{Os}$ ) affords complexes $\mathbf{1} \mathbf{a}, \mathbf{b}$ in good yield (Scheme 1).

The disubstituted EA-bipyridine ligand L2 was obtained following a two-step procedure (Scheme 2) by initially modifying EA-H with ethylene glycol to afford L2a and subsequent coupling to (2,2'-bipyridine)-5,5'-dicarboxylic acid. Both steps employ EDCI and DMAP as the coupling agent and catalyst, respectively. The resulting ligand, $\mathbf{L} 2$, reacts smoothly with $\left[\mathrm{M}\left(\eta^{6}-p \text {-cymene }\right) \mathrm{Cl}\right]_{2} \mathrm{Cl}_{2} \quad(\mathrm{M}=\mathrm{Ru}, \mathrm{Os})$ to afford complexes $\mathbf{2 a , b}$. 
Scheme 2. Synthesis of Ligand L2 and Complexes 2a,b<smiles>C=C(CC)C(=O)c1ccc(OCC(=O)O)c(Cl)c1C(=O)C(=O)OCC(=O)OCCO</smiles>

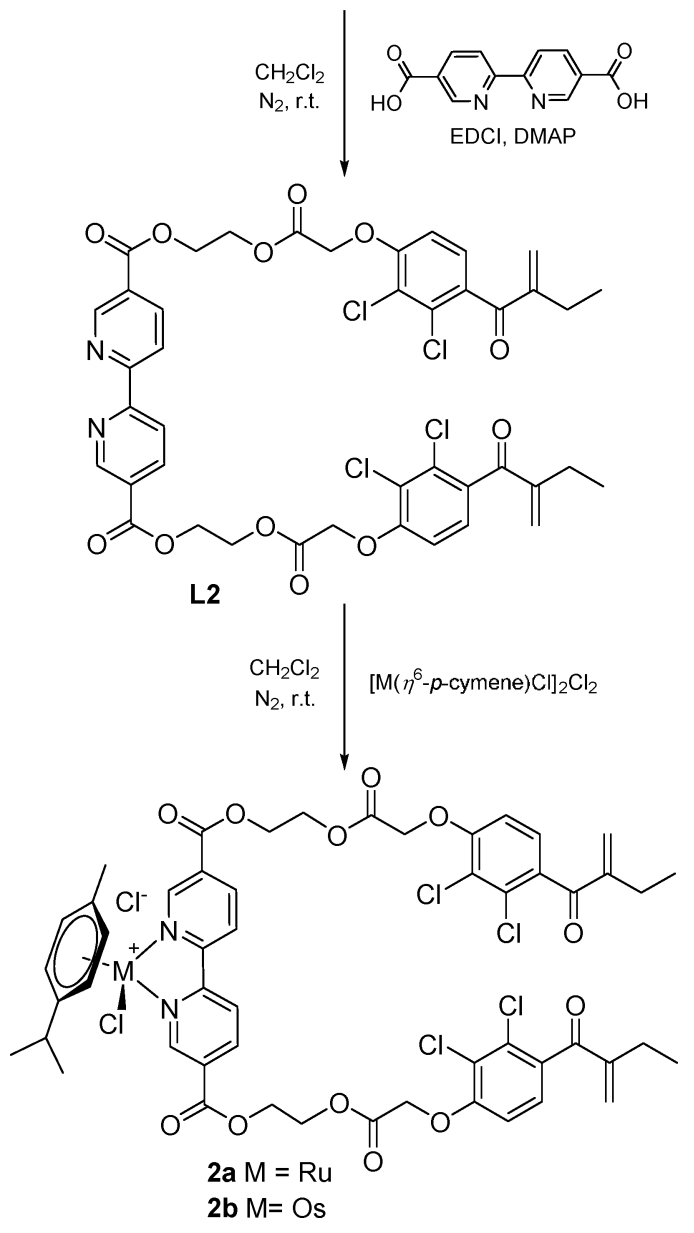

The ligands and complexes were fully characterized by ${ }^{1} \mathrm{H}$ and ${ }^{13} \mathrm{C}$ NMR spectroscopy, mass spectrometry, IR spectroscopy and elemental analysis (see the Experimental Section for full details). The asymmetric bidentate ligand $\mathbf{L 1}$ induces chirality at the metal center in $\mathbf{1} \mathbf{a}, \mathbf{b}$, resulting in loss of the 2fold symmetry of the $\eta^{6}$-p-cymene moiety, ${ }^{65}$ and thus, $\mathbf{1 a}, \mathbf{b}$ were obtained as a racemic mixture.

The ${ }^{1} \mathrm{H}$ NMR spectra of $\mathbf{1 a}, \mathbf{b}$ contain four separate doublets corresponding to the aromatic protons of the $p$-cymene ring and two doublets attributable to the isopropyl group, one for each methyl group, these resonances revealing the stereogenic and chirotopic nature of the metal center (local $C_{1}$ symmetry). ${ }^{65}$ The ${ }^{1} \mathrm{H}$ NMR spectra of ligand $\mathbf{L 1}$ and the corresponding complexes $\mathbf{1 a}, \mathbf{b}$ exhibit peaks which show that the protons $\alpha$ to the $\mathrm{N}$ atoms of the bipyridine unit are strongly influenced by coordination to the metal ion; for $\mathbf{L} \mathbf{1}$ peaks corresponding to the $\alpha$ protons appear at 8.65 and $8.53 \mathrm{ppm}$ and are observed at 9.41 and $9.28 \mathrm{ppm}$ in $1 \mathrm{a}$ and at 9.34 and $9.22 \mathrm{ppm}$ in $\mathbf{1 b}$ (for all of the compounds the signals observed at higher frequencies may be attributed to the EA-modified pyridine ring, whereas the peaks at lower frequencies correspond to the pyridine ring substituted with the methyl group). For the corresponding $\mathrm{C}$ atoms a similar shift to higher frequencies is observed upon coordination of $\mathbf{L 1}(\mathbf{L} \mathbf{1}, 150.3$ and $149.7 \mathrm{ppm} ; 1 \mathrm{a}, 156.7$ and $156.1 \mathrm{ppm} ; \mathbf{1 b}, 156.1$ and 156.0 ppm). Coordination of ligand $\mathbf{L} 2$ to the metal centers leads to a shift of all the peaks corresponding to the pyridine rings to higher frequencies.

The structure of the compounds was further confirmed by electrospray ionization mass spectrometry. For the ligands L1 and $\mathbf{L} \mathbf{2}$ the representative parent peak appears at $[\mathrm{M}+\mathrm{H}]^{+}$, and for the complexes $\mathbf{1} \mathbf{a}, \mathbf{b}$ and $\mathbf{2} \mathbf{a}, \mathbf{b}$ the highest mass peak corresponds to the $[\mathrm{M}-\mathrm{Cl}]^{+}$ion. Moreover, all of the complexes are stable in DMSO solutions used for the biological tests (see Figures S5 and S6 in the Supporting Information).

The crystal structure of $\mathbf{1} \mathbf{b}$ was established in the solid state by single-crystal X-ray diffraction (Figure 2), confirming the

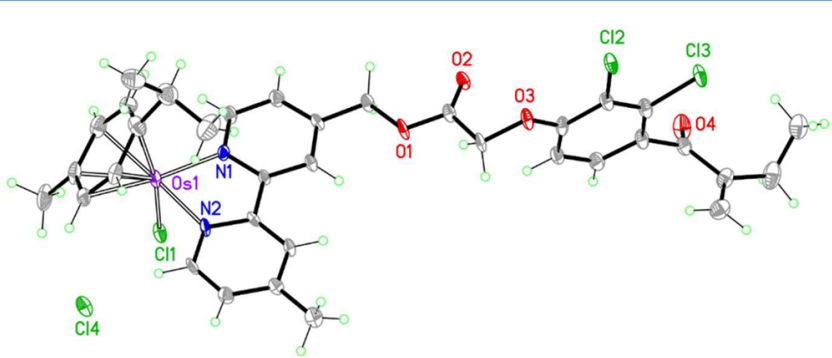

Figure 2. ORTEP representation of complex $\mathbf{1 b}$ (thermal ellipsoids are $40 \%$ equiprobability envelopes, and $\mathrm{H}$ atoms are spheres of arbitrary diameter).

expected structure. The structure comprises the classical threelegged piano-stool arrangement. The coordination sphere of the Os(II) ion contains an $\eta^{6}$-p-cymene ring, the bidentate ligand, and a chloride ligand. The average Os $-\eta^{6}$ centroid distance is $1.675(4) \AA$. The bipyridine ligand forms essentially a planar five-membered chelating ring, the two pyridine rings of the bipyridne ligands being almost coplanar (dihedral angle N1$\mathrm{C}-\mathrm{C}-\mathrm{N} 22.2(11)^{\circ}$ ) (Figure S1). The the chelate bite angle $\mathrm{N} 1-\mathrm{Os}-\mathrm{N} 2$ is $76.6(3)^{\circ}$, and the $\mathrm{N} 1-\mathrm{Os}-\mathrm{Cl}$ and $\mathrm{N} 2-\mathrm{Os}-\mathrm{Cl}$ angles are $84.6(2)$ and $86.1(2)^{\circ}$, respectively. The $\mathrm{Os}-\mathrm{N}_{\mathrm{py}}$ bond lengths are 2.090(7) $\AA$ (for Os-N1) and 2.103(7) $\AA$ (for Os-N2), and the Os-Cl bond length is 2.404(3) $\AA$. The packing in the crystal comprises intermolecular paralleldisplaced $\pi-\pi$ stacking interactions between the bipyridine ligands of two adjacent molecules (centroid-centroid distance $3.955 \AA$, Figure S2 in the Supporting Information). Another key interaction in $\mathbf{1 b}$ comprises a three-center hydrogen bond between the chloride counteranion (acting as a bifurcated acceptor) and the hydrogen atoms of $\mathrm{CH}_{3} \mathrm{OH}$ and $\mathrm{CHCl}_{3}$ solvent molecules (see Figure S4 and Table S1 in the Supporting Information for the parameters characterizing the hydrogen bonding interaction).

Human GST P1-1 used for the experiments was expressed in and purified from E. coli using a protocol reported earlier. ${ }^{66,67}$ The inhibitory activity of the compounds was investigated by determining the residual catalytic activity of the enzyme using 
the CDNB-GSH (1-chloro-2,4-dinitrobenzene-glutathione) assay. ${ }^{68}$ In brief, the enzyme was treated with varying concentrations of complexes $\mathbf{1} \mathbf{a}, \mathbf{b}$ and $\mathbf{2} \mathbf{a}, \mathbf{b}$ to determine the $\mathrm{IC}_{50}$ value i.e., the concentration at which $50 \%$ enzyme activity is inhibited.

Complexes 1a,b (containing only one pendant ethacrynic acid unit) inhibit GST P1-1 activity slightly more efficiently than EA-H ${ }^{58}$ (see Table 1). Notably, complexes 2a,b,

\section{Table 1. Inhibition of Human GST P1-1 ${ }^{a}$}

\begin{tabular}{ll} 
compound & GST P1-1 \\
RAPTA-C & $>200^{b}$ \\
EA & $12.0^{b}$ \\
$\mathbf{1 a}$ & $9.06 \pm 1.43$ \\
$\mathbf{1 b}$ & $9.53 \pm 3.32$ \\
$\mathbf{2 a}$ & $3.96 \pm 0.98$ \\
$\mathbf{2 b}$ & $3.98 \pm 1.68$ \\
${ }^{a_{\mathrm{IC}}}{ }_{50}$ values $(\mu \mathrm{M})$ are given as the mean \pm SD. ${ }^{b}$ Values taken from ref \\
58. & \\
\hline
\end{tabular}

containing two EA units, are more potent inhibitors of GST P1-1. Furthermore, treatment with $\mathbf{2 b}$ results in almost complete inhibition of GST P1-1 activity (residual activity $<5 \%)$ at the highest concentration tested $(100 \mu \mathrm{m})$, whereas there is more significant residual GST P1-1 activity $(\sim 14 \%)$ after treatment with $\mathbf{1 a}, \mathbf{b}$ at the same concentration (see Figure S7 in the Supporting Information). These findings suggest a role of the organometallic ruthenium fragment in the inhibition of GST P1-1, potentially involving direct coordination of the metal ion to the enzyme as established previously. ${ }^{58}$

The cytotoxicity of ligands $\mathbf{L} \mathbf{1}$ and $\mathbf{L} \mathbf{2}$, complexes $\mathbf{1 a}, \mathbf{b}$ and $\mathbf{2 a}, \mathbf{b}$, and relevant control compounds was assessed in two cancer cell lines (human ovarian carcinoma cisplatin-sensitive A2780 and -resistant A2780cisR) and human embryonic kidney (HEK-293) cells used as a model for normal cells. Cytotoxicity studies were carried out at $37{ }^{\circ} \mathrm{C}$ for $72 \mathrm{~h}$ (Table 2 and Figure S8 in the Supporting Information) using an MTT test (MTT = 3-(4,5-dimethyl-2-thiazolyl)-2,5-diphenyl- $2 \mathrm{H}$-tetrazolium bromide) to monitor cell viability. All of the complexes are more cytotoxic than RAPTA-C ${ }^{69}$ and its Os analogue, termed OAPTA-C $\left(\left[\mathrm{Os}^{\mathrm{II}}\left(\eta^{6}-p\right.\right.\right.$-cymene $\left.)(\mathrm{PTA}) \mathrm{Cl}_{2}\right]$, PTA $=1,3,5-$

Table 2. $\mathrm{IC}_{50}$ Values $(\boldsymbol{\mu M})$ Determined for RAPTA-C, OAPTA-C, EA-H, Ligands L1 and L2, and Complexes 1a,b and 2a,b towards Human Ovarian Cancer A2780 and A2780cisR (Cisplatin Sensitive and Resistant) and Immortalized Human Embryonic Kidney HEK-293 Cells Using the MTT Assay ${ }^{a}$

\begin{tabular}{llll} 
compound & \multicolumn{1}{c}{ A2780 } & A2780cisR & \multicolumn{1}{c}{ HEK-293 } \\
RAPTA-C & $>200^{b}$ & $>200^{b}$ & $>1000^{b}$ \\
OAPTA-C & $>200$ & $>200$ & $>200$ \\
EA & $40 \pm 3$ & $53 \pm 5$ & $39 \pm 1$ \\
L1 & $14.44 \pm 1.97$ & $24.3 \pm 0.9$ & $15.9 \pm 5.1$ \\
1a & $26.1 \pm 1.6$ & $84 \pm 1$ & $67 \pm 2$ \\
1b & $18.81 \pm 0.85$ & $59 \pm 7$ & $42.6 \pm 1.0$ \\
L2 & $73 \pm 3$ & $639 \pm 7$ & $157 \pm 20$ \\
2a & $7.77 \pm 0.01$ & $8.37 \pm 1.01$ & $6.16 \pm 1.79$ \\
2b & $9.31 \pm 2.62$ & $15.7 \pm 1.3$ & $12.80 \pm 0.18$ \\
cisplatin & 0.95 & 11.14 & 16.51
\end{tabular}

${ }^{a}$ Values are given as the mean \pm SD. ${ }^{b}$ Values taken from ref 69. triaza-7-phosphatricyclo[3.3.1.1]decane). Ligand $\mathbf{L} 1$ as well as the complexes containing two EA units, i.e. $2 \mathbf{a}, \mathbf{b}$, present a higher antiproliferative activity on all the tested cell lines in comparison to EA-H. For complexes $\mathbf{1 a}, \mathbf{b}$ with only one EA unit a ca. 3-fold decrease in cytotoxicity against the cisplatinresistant ovarian carcinoma cells A2780cisR, in comparison to the cisplatin-sensitive cells A2780 cells, is observed. For these compounds the attachment of the organometallic $\mathrm{M}^{\mathrm{II}}-p$-cymene unit to ligand L1 leads to a decrease in cytotoxicity to both A2780 and A2780cisR cells, whereas the Os(II) complex is more active than the $\mathrm{Ru}(\mathrm{II})$ complex. The $\mathrm{IC}_{50}$ values determined for $\mathbf{1} \mathbf{a}, \mathbf{b}$ on the nontumoral HEK-293 cells are ca. 2-fold higher in comparison to those of the A2780 cells.

Interestingly, ligand L1, derivatized with one EA unit, has a higher antiproliferative activity in comparison to EA-H on all the tested cell lines, whereas attachment of two EA units in L2 is accompanied by a significant decrease in cytotoxicity.

Attachment of an organometallic $\mathrm{M}^{\mathrm{II}}$ - $p$-cymene moiety to L2 in $\mathbf{2 a}, \mathbf{b}$ leads to a significant increase in the antiproliferative activity toward all tested cell lines. The ruthenium complex with two EA moieties, 2a, displays very similar $\mathrm{IC}_{50}$ values in both the A2780 and A2780cisR cell lines $(7.77$ and $8.37 \mu \mathrm{M}$, respectively), and the Os analogue is slightly less cytotoxic with values of 9.31 and $15.7 \mu \mathrm{M}$, respectively. However, 2a,b are both cytotoxic to the nontumorigenic HEK-293 cells with $\mathrm{IC}_{50}$ values of 6.16 and $12.8 \mu \mathrm{M}$, respectively. The relatively potent cyctotoxicity of $\mathbf{2 a}, \mathbf{b}$ cannot be attributed entirely to the ability of the complexes to inhibit GST activity but is presumably also in part due to the increased hydrophobicity of the complexes relative to RAPTA-C and OAPTA-C, which potentially enhances drug uptake and, consequently, their cytotoxic effects. Overall, complexes 1a,b are less cytotoxic in all three cell lines than $\mathbf{2 a}, \mathbf{b}$. Since the former pair are chiral but obtained as a racemic mixture, it is possible that the individual optical isomers present different antiproliferative activities. Indeed, it has been previously shown that different optical isomers of chiral-atmetal or chiral-at-ligand ruthenium(II) and Os(II) arene complexes may or may not exhibit similar cytotoxicities. ${ }^{70-73}$ Interestingly, in all three cell lines, for the $\mathrm{Ru} /$ Os pair $\mathbf{1} \mathbf{a}, \mathbf{b}$ the osmium complex is more cyctotoxic, whereas for the pair $\mathbf{2 a} \mathbf{a} \mathbf{b}$ the ruthenium complex presents higher antiproliferative activity. Such a difference is not entirely unexpected, as there appears to be no clear correlation from the multitude of studies reporting analogues based on these two metals. ${ }^{74}$

\section{CONCLUSIONS}

In summary, we have shown that incorporation of organometallic $p$-cymene ruthenium(II) or osmium(II) centers to EAderived compounds enhances the inhibition of GST P1-1 activity, an enzyme expressed in cancer cells and responsible for drug resistance. The enhanced inhibition is particularly notable for $\mathbf{2} \mathbf{a}, \mathbf{b}$, in which the metal ion is located between two EA moieties. These two compounds are also the most cytotoxic of the series, displaying similar antiproliferative activity to both A2780 and A2780cisR cells, indicative of overcoming GST-type resistance in the latter cell line which is known to overexpress GSTs. ${ }^{11}$ Interestingly, while there is no difference between the pairs of ruthenium and osmium complexes in terms of GST P11 inhibition and only a slight difference with respect to antiproliferative activity, the metal ions appear to play a critical role, i.e. in comparison to the free ligands, implying that direct interactions with the enzyme might be involved. 


\section{EXPERIMENTAL SECTION}

General Experimental Conditions. $\mathrm{RuCl}_{3} \cdot 3 \mathrm{H}_{2} \mathrm{O}$ was obtained from Precious Metals Online, and all other chemicals were purchased from from Aldrich, AlfaAesar, Acros, ABCR, or TCI Chemicals and used without further purification. Reactions were performed under an inert atmosphere of $\mathrm{N}_{2}$ using Schlenk techniques with solvents dried using drying columns. The dimers $\left[\mathrm{Ru}\left(\eta^{6}-p \text {-cymene }\right) \mathrm{Cl}_{2}\right]_{2} \mathrm{Cl}_{2}$ and $\left[\mathrm{Os}\left(\eta^{6}-p \text {-cymene }\right) \mathrm{Cl}\right]_{2} \mathrm{Cl}_{2}$ were prepared and purified according to literature procedures. ${ }^{75} \mathrm{H}(400.13 \mathrm{MHz})$ and ${ }^{13} \mathrm{C}(100.62 \mathrm{MHz})$ NMR spectra were recorded on a Bruker Avance II 400 spectrometer at $298 \mathrm{~K}$ unless otherwise stated. The chemical shifts are reported in parts per million ( $\mathrm{ppm}$ ) and referenced to residual solvent peaks $\left(\mathrm{CDCl}_{3},{ }^{1} \mathrm{H} \delta 7.26,{ }^{13} \mathrm{C}\left\{{ }^{1} \mathrm{H}\right\} \delta 77.16\right.$ ppm; MeOD- $d_{4},{ }^{1} \mathrm{H} \delta 3.31$, $\left.{ }^{13} \mathrm{C}\left\{{ }^{1} \mathrm{H}\right\} \delta 49.00 \mathrm{ppm}\right),{ }^{76}$ and coupling constants $(J)$ are reported in hertz $(\mathrm{Hz})$. IR spectra were recorded on a PerkinElmer Spectrum One FT-IR spectrometer at room temperature. Electrospray ionization mass spectra (ESI-MS) were obtained on a Thermo-Finnigan LCQ Deca XP Plus quadropole ion-trap instrument operated in positive-ion mode. Elemental analyses were carried out by the microanalytical laboratory at the Institute of Chemical Sciences and Engineering (EPFL). Melting points were determined using a SMP3 Stuart Melting Point Apparatus and are uncorrected. Reactions were monitored by TLC using Merck TLC silica gel coated aluminum sheets $60 \mathrm{~F}_{254}$ and visualized with $\mathrm{UV}$ at $254 \mathrm{~nm}$ and $\mathrm{KMnO}_{4}$ stain. Compounds were purified by column flash chromatography on silica gel using the elution systems indicated.

Syntheses of the Ligands. Synthesis of $\left(4^{\prime}-\right.$ Methyl- $\left[2,2^{\prime}-\right.$ bipyridin]-4-yl)methyl-2-(2,3-dichloro-4-(2-methylenebutanoyl)phenoxy)acetate (L1). To a solution of ethacrynic acid (1.090 g, 1.2 equiv) in $\mathrm{CH}_{2} \mathrm{Cl}_{2}(100 \mathrm{~mL})$ were added $\mathrm{EDCI}(0.804 \mathrm{~g}, 1.4$ equiv $), 4^{\prime}$ methyl-[2,2'-bipyridin]-4-yl)methanol (0.600 g, 1 equiv), and DMAP $(0.110 \mathrm{~g}, 0.3$ equiv). The reaction mixture was stirred at room temperature for $24 \mathrm{~h}$, and then the mixture was diluted with $\mathrm{CH}_{2} \mathrm{Cl}_{2}$ $(50 \mathrm{~mL})$ and washed with $\mathrm{H}_{2} \mathrm{O}(150 \mathrm{~mL})$. The isolated organic phase was further washed with brine $(150 \mathrm{~mL})$, dried over anhydrous $\mathrm{Na}_{2} \mathrm{SO}_{4}$, filtered, and concentrated under reduced pressure. Purification by flash column chromatography using a $\mathrm{CH}_{2} \mathrm{Cl}_{2} /$ $\mathrm{MeOH}$ mixture as eluent afforded the product as a colorless solid (1.276 g, yield 88\%): $\mathrm{mp}\left({ }^{\circ} \mathrm{C}\right): 71-72 ; R_{\mathrm{f}}\left(\mathrm{CH}_{2} \mathrm{Cl}_{2} / \mathrm{MeOH} 9.5 / 0.5\right)$ : $0.543 ;{ }^{1} \mathrm{H}$ NMR $\left(\mathrm{CDCl}_{3}\right) \delta_{\mathrm{H}}(\mathrm{ppm}) 8.65\left(1 \mathrm{H}, \mathrm{dd}, \mathrm{O}-\mathrm{CH}_{2}-(\mathrm{Py}) \mathrm{C}-\mathrm{CH}-\right.$ $\left.\mathrm{CH}-\mathrm{N},{ }^{3} J_{\mathrm{H}, \mathrm{H}}=5.0 \mathrm{~Hz},{ }^{4} J_{\mathrm{H}, \mathrm{H}}=0.4 \mathrm{~Hz}\right), 8.53\left(1 \mathrm{H}, \mathrm{d}, \mathrm{CH}_{3}-(\mathrm{Py}) \mathrm{C}-\mathrm{CH}-\right.$ $\left.\mathrm{CH}-\mathrm{N},{ }^{3} \mathrm{~J}_{\mathrm{H}, \mathrm{H}}=5.0 \mathrm{~Hz}\right), 8.40\left(1 \mathrm{H}, \mathrm{m}, \mathrm{O}-\mathrm{CH}_{2}-(\mathrm{Py}) \mathrm{C}-\mathrm{CH}-\mathrm{C}-\mathrm{N}\right), 8.25$ $\left(1 \mathrm{H}, \mathrm{m}, \mathrm{CH}_{3}\right.$-(Py)C-CH-C-N), $7.24\left(1 \mathrm{H}, \mathrm{dd}, \mathrm{O}-\mathrm{CH}_{2}-(\mathrm{Py}) \mathrm{C}-\mathrm{CH}-\mathrm{CH}-\right.$ $\left.\mathrm{N},{ }^{3} \mathrm{H}_{\mathrm{H}, \mathrm{H}}=5.0 \mathrm{~Hz},{ }^{4} \mathrm{~J}_{\mathrm{H}, \mathrm{H}}=1.7 \mathrm{~Hz}\right), 7.16\left(1 \mathrm{H}, \mathrm{dd}, \mathrm{CH}_{3}-(\mathrm{Py}) \mathrm{C}-\mathrm{CH}-\mathrm{CH}-\right.$ $\left.\mathrm{N},{ }^{3} J_{\mathrm{H}, \mathrm{H}}=5.0 \mathrm{~Hz},{ }^{4} J_{\mathrm{H}, \mathrm{H}}=0.7 \mathrm{~Hz}\right), 7.10(1 \mathrm{H}, \mathrm{d},(\mathrm{Ar}) \mathrm{CH}-\mathrm{C}-(\mathrm{C}=\mathrm{O})$, $\left.{ }^{3} J_{\mathrm{H}, \mathrm{H}}=8.5 \mathrm{~Hz}\right), 6.80\left(1 \mathrm{H}, \mathrm{d},(\mathrm{Ar}) \mathrm{CH}-\mathrm{C}-\mathrm{O}-\mathrm{CH}_{2}-(\mathrm{C}=\mathrm{O}),{ }^{3} \mathrm{~J}_{\mathrm{H}, \mathrm{H}}=8.5\right.$ $\mathrm{Hz}), 5.90\left(1 \mathrm{H}, \mathrm{t}\right.$, cis $\left.(\mathrm{CH}=\mathrm{C})-\mathrm{CH}_{2}-\mathrm{CH}_{3},{ }^{4} J_{\mathrm{H}, \mathrm{H}}=1.4 \mathrm{~Hz}\right), 5.55(1 \mathrm{H}, \mathrm{s}$, trans $\left.(\mathrm{CH}=\mathrm{C})-\mathrm{CH}_{2}-\mathrm{CH}_{3}\right), 5.33\left(2 \mathrm{H}, \mathrm{s}, \mathrm{O}-\mathrm{CH}_{2}-(\mathrm{Py}) \mathrm{C}-\mathrm{CH}-\mathrm{CH}-\mathrm{N}\right)$, $4.88\left(2 \mathrm{H}, \mathrm{s},(\mathrm{Ar}) \mathrm{C}-\mathrm{O}-\mathrm{CH}_{2}-(\mathrm{C}=\mathrm{O})\right), 2.45\left(2 \mathrm{H}, \mathrm{m},\left(\mathrm{CH}_{2}=\mathrm{C}\right)-\mathrm{CH}_{2}-\right.$ $\left.\mathrm{CH}_{3},{ }^{3} J_{\mathrm{H}, \mathrm{H}}=7.5 \mathrm{~Hz}\right), 2.44\left(3 \mathrm{H}, \mathrm{s}, \mathrm{CH}_{3}\right.$-(Py)C-CH-CH-N), $1.13(3 \mathrm{H}$, t, $\left.\left(\mathrm{CH}_{2}=\mathrm{C}\right)-\mathrm{CH}_{2}-\mathrm{CH}_{3},{ }^{4} \mathrm{~J}_{\mathrm{H}, \mathrm{H}}=7.5 \mathrm{~Hz}\right) ;{ }^{13} \mathrm{C} \mathrm{NMR}\left(\mathrm{CDCl}_{3}\right) \delta_{\mathrm{C}}$ (ppm) 195.8 (1C, $\left.(\mathrm{Ar}) \mathrm{C}-(\mathrm{C}=\mathrm{O})-\left(\mathrm{C}=\mathrm{CH}_{2}\right)\right), 167.6(1 \mathrm{C},(\mathrm{Ar}) \mathrm{C}-\mathrm{O}-$ $\left.\mathrm{CH}_{2}-(\mathrm{C}=\mathrm{O})-\mathrm{O}\right), 156.8$ (1C, O- $\left.\mathrm{CH}_{2}-(\mathrm{Py}) \mathrm{C}-\mathrm{CH}-\mathrm{C}-\mathrm{N}\right), 155.4$ (1C, $\left.(\mathrm{Ar}) \mathrm{CH}-\mathrm{C}-\mathrm{O}-\mathrm{CH}_{2}-(\mathrm{C}=\mathrm{O})\right), 155.3\left(1 \mathrm{C}, \mathrm{CH}_{3}-(\mathrm{Py}) \mathrm{C}-\mathrm{CH}-\mathrm{C}-\mathrm{N}\right), 150.3$ (1C, O- $\left.\mathrm{CH}_{2}-(\mathrm{Py}) \mathrm{C}-\mathrm{CH}-\mathrm{CH}-\mathrm{N}\right), 149.7$ (1C, $\left.\mathrm{CH}_{3}-(\mathrm{Py}) \mathrm{C}-\mathrm{CH}-\mathrm{CH}-\mathrm{N}\right)$, $149.0\left(1 \mathrm{C}, \mathrm{CH}_{3}-\mathrm{CH}_{2}-\left(\mathrm{C}=\mathrm{CH}_{2}\right)\right), 148.7\left(1 \mathrm{C}, \mathrm{O}-\mathrm{CH}_{2}-(\mathrm{Py}) \mathrm{C}-\mathrm{CH}-\mathrm{CH}-\right.$ $\mathrm{N}), 144.9$ (1C, $\left.\mathrm{CH}_{3}-(\mathrm{Py}) \mathrm{C}-\mathrm{CH}-\mathrm{CH}-\mathrm{N}\right), 134.2(1 \mathrm{C}, \mathrm{Cl}-(\mathrm{Ar}) \mathrm{C}-\mathrm{C}-(\mathrm{C}=$ $\mathrm{O})), 131.7$ (1C, Cl-(Ar)C-C- $(\mathrm{C}=\mathrm{O})), 128.7\left(1 \mathrm{C},\left(\mathrm{CH}_{2}=\mathrm{C}\right)-\mathrm{CH}_{2}-\right.$ $\left.\mathrm{CH}_{3}\right), 126.9$ (1C, $\left.(\mathrm{Ar}) \mathrm{CH}-\mathrm{C}-(\mathrm{C}=\mathrm{O})\right), 125.2\left(1 \mathrm{C}, \mathrm{CH}_{3}-(\mathrm{Py}) \mathrm{C}-\mathrm{CH}-\right.$ $\mathrm{CH}-\mathrm{N}), 123.6$ (1C, Cl-(Ar)C-C-O-CH $-(\mathrm{C}=\mathrm{O})), 122.3\left(1 \mathrm{C}, \mathrm{CH}_{3}-\right.$ (Py)C-CH-C-N), 122.0 (1C, O-CH $-($ Py)C-CH-CH-N), 119.6 (1C, $\left.\mathrm{O}-\mathrm{CH}_{2}-(\mathrm{Py}) \mathrm{C}-\mathrm{CH}-\mathrm{C}-\mathrm{N}\right), 111.0\left(1 \mathrm{C}, \quad(\mathrm{Ar}) \mathrm{CH}-\mathrm{C}-\mathrm{O}-\mathrm{CH}_{2}-(\mathrm{C}=\mathrm{O})\right)$, $66.3\left(1 \mathrm{C},(\mathrm{Ar}) \mathrm{C}-\mathrm{O}-\mathrm{CH}_{2}-(\mathrm{C}=\mathrm{O})\right), 65.6\left(1 \mathrm{C}, \mathrm{O}-\mathrm{CH}_{2}-(\mathrm{Py}) \mathrm{C}-\mathrm{CH}-\right.$ $\mathrm{CH}-\mathrm{N}), 23.5\left(1 \mathrm{C},\left(\mathrm{CH}_{2}=\mathrm{C}\right)-\mathrm{CH}_{2}-\mathrm{CH}_{3}\right), 21.4\left(1 \mathrm{C}, \mathrm{CH}_{3}-(\mathrm{Py}) \mathrm{C}-\mathrm{CH}-\right.$ CH-N), $12.5\left(1 \mathrm{C},\left(\mathrm{CH}_{2}=\mathrm{C}\right)-\mathrm{CH}_{2}-\mathrm{CH}_{3}\right)$; IR $\left(\nu, \mathrm{cm}^{-1}\right) 2925(\mathrm{C}-\mathrm{H}$, $\left.\mathrm{CH}_{2}, \mathrm{CH}_{3}\right), 1760(\mathrm{C}=\mathrm{O}$, ester $), 1664(\mathrm{C}=\mathrm{O}$, ketone, $\mathrm{C}=\mathrm{C}$, alkene), 1584, 1462, 1381 (ring skeleton $\mathrm{C}=\mathrm{C}, \mathrm{C}-\mathrm{C}, \mathrm{C}=\mathrm{N}, \mathrm{C}-\mathrm{N}$ ), 1291, 1258, 1186, 1076 (C-O, ester, ether), 820 (C-H aromatic); ESIMS(+) $m / z$ 485.14 $[\mathrm{M}]^{+}$, calcd for $\mathrm{C}_{25} \mathrm{H}_{22} \mathrm{Cl}_{2} \mathrm{~N}_{2} \mathrm{O}_{4} 485.36$ (the isotopic pattern corresponds well to the calculated pattern). Anal. Calcd for $\mathrm{C}_{25} \mathrm{H}_{22} \mathrm{Cl}_{2} \mathrm{~N}_{2} \mathrm{O}_{4}$ : C, 61.87; H, 4.57; N, 5.77. Found: C, 61.77; H, 4.63; N, 5.48 .

Synthesis of 2-Hydroxyethyl-2-(2,3-dichloro-4-(2methylenebutanoyl)phenoxy)acetate (L2a). To a solution of ethacynic acid (4.000 g, 1 equiv) in $\mathrm{CH}_{2} \mathrm{Cl}_{2}(\mathrm{~mL})$ were added EDCI ( $3.035 \mathrm{~g}, 1.2$ equiv), ethylene glycol ( $3 \mathrm{~mL}, 4$ equiv), and DMAP $(0.322 \mathrm{~g}, 0.2$ equiv). The reaction mixture was stirred at room temperature for $24 \mathrm{~h}$, and then the mixture was diluted with $\mathrm{CH}_{2} \mathrm{Cl}_{2}$ $(50 \mathrm{~mL})$ and washed with $\mathrm{H}_{2} \mathrm{O}(150 \mathrm{~mL})$ and the isolated organic phase was further washed with brine $(150 \mathrm{~mL})$, dried over anhydrous $\mathrm{Na}_{2} \mathrm{SO}_{4}$, filtered, and concentrated under reduced pressure. Purification by flash column chromatography using a Hex/EtOAc mixture as eluent afforded the product as a white solid (3.459 g, yield 76\%): $\mathrm{Mp}\left({ }^{\circ} \mathrm{C}\right)$ 94.5-95.5; $R_{\mathrm{f}}$ (Hex/AcOEt 4/6) 0.260; ${ }^{1} \mathrm{H}$ NMR $\left(\mathrm{CDCl}_{3}\right) \delta_{\mathrm{H}}(\mathrm{ppm}) 7.10\left(1 \mathrm{H}, \mathrm{d},(\mathrm{Ar}) \mathrm{CH}-\mathrm{C}-(\mathrm{C}=\mathrm{O}),{ }^{3} J_{\mathrm{H}, \mathrm{H}}=8.5 \mathrm{~Hz}\right)$, $6.78\left(1 \mathrm{H}, \mathrm{d},(\mathrm{Ar}) \mathrm{CH}-\mathrm{C}-\mathrm{O}-\mathrm{CH}_{2}-(\mathrm{C}=\mathrm{O}),{ }^{3} J_{\mathrm{H}, \mathrm{H}}=8.5 \mathrm{~Hz}\right), 5.92(1 \mathrm{H}, \mathrm{t}$, cis $\left.(\mathrm{CH}=\mathrm{C})-\mathrm{CH}_{2}-\mathrm{CH}_{3},{ }^{4} \mathrm{~J}_{\mathrm{H}, \mathrm{H}}=1.4 \mathrm{~Hz}\right), 5.57(1 \mathrm{H}, \mathrm{s}$, trans $(\mathrm{CH}=\mathrm{C})-$ $\left.\mathrm{CH}_{2}-\mathrm{CH}_{3}\right), 4.78\left(2 \mathrm{H}, \mathrm{s},(\mathrm{Ar}) \mathrm{C}-\mathrm{O}-\mathrm{CH}_{2}-(\mathrm{C}=\mathrm{O})-\mathrm{O}\right), 4.30-4.32(2 \mathrm{H}$, $\left.\mathrm{m},(\mathrm{C}=\mathrm{O})-\mathrm{O}-\mathrm{CH}_{2}-\mathrm{CH}_{2}-\mathrm{OH}\right), 3.80-3.83\left(2 \mathrm{H}, \mathrm{m},(\mathrm{C}=\mathrm{O})-\mathrm{O}-\mathrm{CH}_{2}-\right.$ $\left.\mathrm{CH}_{2}-\mathrm{OH}\right), 2.42\left(2 \mathrm{H}, \mathrm{m},\left(\mathrm{CH}_{2}=\mathrm{C}\right)-\mathrm{CH}_{2}-\mathrm{CH}_{3},{ }^{3} \mathrm{~J}_{\mathrm{H}, \mathrm{H}}=7.5 \mathrm{~Hz}\right), 1.11$ $\left(3 \mathrm{H}, \mathrm{t},\left(\mathrm{CH}_{2}=\mathrm{C}\right)-\mathrm{CH}_{2}-\mathrm{CH}_{3},{ }^{3} J_{\mathrm{H}, \mathrm{H}}=7.5 \mathrm{~Hz}\right) ;{ }^{13} \mathrm{C} \mathrm{NMR}\left(\mathrm{CDCl}_{3}\right) \delta_{\mathrm{C}}$ (ppm) $196.0\left(1 \mathrm{C},(\mathrm{Ar}) \mathrm{C}-(\mathrm{C}=\mathrm{O})-\left(\mathrm{C}=\mathrm{CH}_{2}\right)\right), 168.1(1 \mathrm{C},(\mathrm{Ar}) \mathrm{C}-\mathrm{O}-$ $\left.\mathrm{CH}_{2}-(\mathrm{C}=\mathrm{O})\right), 155.5$ (1C, (Ar)CH-C-O), $150.2\left(1 \mathrm{C}, \mathrm{CH}_{3}-\mathrm{CH}_{2}-\right.$ $\left.\left(\mathrm{C}=\mathrm{CH}_{2}\right)\right), 134.0(1 \mathrm{C}, \mathrm{Cl}-(\mathrm{Ar}) \mathrm{C}-\mathrm{C}-(\mathrm{C}=\mathrm{O})), 131.6(1 \mathrm{C}, \mathrm{Cl}-(\mathrm{Ar}) \mathrm{C}-\mathrm{C}-$ $(\mathrm{C}=\mathrm{O})), 128.9\left(\mathrm{IC},\left(\mathrm{CH}_{2}=\mathrm{C}\right)-\mathrm{CH}_{2}-\mathrm{CH}_{3}\right), 126.9(1 \mathrm{C},(\mathrm{Ar}) \mathrm{CH}-\mathrm{C}-$ $(\mathrm{C}=\mathrm{O})), 123.4\left(1 \mathrm{C}, \mathrm{Cl}-(\mathrm{Ar}) \mathrm{C}-\mathrm{C}-\mathrm{O}-\mathrm{CH}_{2}-(\mathrm{C}=\mathrm{O})\right), 111.0(1 \mathrm{C},(\mathrm{Ar})$ $\left.\mathrm{CH}-\mathrm{C}-\mathrm{O}-\mathrm{CH}_{2}\right), 67.0\left(1 \mathrm{C},(\mathrm{Ar}) \mathrm{C}-\mathrm{O}-\mathrm{CH}_{2}-(\mathrm{C}=\mathrm{O})-\mathrm{O}\right), 66.3(1 \mathrm{C},(\mathrm{C}=$ $\left.\mathrm{O})-\mathrm{O}-\mathrm{CH}_{2}-\mathrm{CH}_{2}-\mathrm{OH}\right), 60.8 \quad\left(1 \mathrm{C}, \quad(\mathrm{C}=\mathrm{O})-\mathrm{O}-\mathrm{CH}_{2}-\mathrm{CH}_{2}-\mathrm{OH}\right), 23.5$ $\left(1 \mathrm{C},\left(\mathrm{CH}_{2}=\mathrm{C}\right)-\mathrm{CH}_{2}-\mathrm{CH}_{3}\right), 12.5\left(1 \mathrm{C},\left(\mathrm{CH}_{2}=\mathrm{C}\right)-\mathrm{CH}_{2}-\mathrm{CH}_{3}\right)$; IR $(\nu$, $\left.\mathrm{cm}^{-1}\right)$ : $3509(\mathrm{O}-\mathrm{H}) ; 2975-2880\left(\mathrm{C}-\mathrm{H}, \mathrm{CH}_{2}, \mathrm{CH}_{3}\right), 1736(\mathrm{C}=\mathrm{O}$, ester), $1661(\mathrm{C}=\mathrm{O}$, ketone, $\mathrm{C}=\mathrm{C}$, alkene), 1587, 1471, 1383 (ring skeleton $\mathrm{C}=\mathrm{C}, \mathrm{C}-\mathrm{C}) ; 1291,1229,1204,1075(\mathrm{C}-\mathrm{O}$, ester, ether), 891 (C-H aromatic); ESI-MS(+): $\mathrm{m} / z 347.01[\mathrm{M}]^{+}$, calcd for $\mathrm{C}_{15} \mathrm{H}_{16} \mathrm{Cl}_{2} \mathrm{O}_{5} 347.19$ (the isotopic pattern corresponds well to the calculated pattern). Anal. Calcd for $\mathrm{C}_{15} \mathrm{H}_{16} \mathrm{Cl}_{2} \mathrm{O}_{5}: \mathrm{C}, 51.89 ; \mathrm{H}, 4.65$. Found: C, 51.95; H, 4.69;

Synthesis of bis(2-(2-(2,3-dichloro-4-(2-methylenebutanoyl)phenoxy)acetoxy)ethyl)-(2,2'-bipyridine)-5, 5'-dicarboxylate (L2). To a suspension of $\left[2,2^{\prime}\right.$-bipyridine $]-5,5^{\prime}$-dicarboxylic acid $(0.765 \mathrm{~g}$, 1 equiv) in a mixture of $\mathrm{CH}_{2} \mathrm{Cl}_{2}(20 \mathrm{~mL})$ and $\left(\mathrm{CH}_{3}\right)_{2} \mathrm{NC}(\mathrm{O}) \mathrm{H}(40$ $\mathrm{mL}$ ) were added EDCI (1.441 g, 2.4 equiv), L2a (2.500 g, 2.3 equiv), and DMAP $(0.230 \mathrm{~g}, 0.6$ equiv). The reaction mixture was stirred at room temperature for $48 \mathrm{~h}$ and then the mixture was concentrated to dryness under reduced pressure and the crude product was solubilized in $\mathrm{CH}_{2} \mathrm{Cl}_{2}(150 \mathrm{~mL})$ and washed with $\mathrm{H}_{2} \mathrm{O}(150 \mathrm{~mL})$. The isolated organic phase was further washed with brine $(150 \mathrm{~mL})$, dried over anhydrous $\mathrm{Na}_{2} \mathrm{SO}_{4}$, filtered, and concentrated under reduced pressure. Purification by flash column chromatography using a Hex/EtOAc mixture as eluent afforded the product as a white solid $(0.875 \mathrm{~g}$, yield 28\%): $\mathrm{mp}\left({ }^{\circ} \mathrm{C}\right) 136-137 ; R_{\mathrm{f}}\left(\mathrm{Hex} / \mathrm{EtOAc} 3 / 7\right.$ (v/v)) 0.729; ${ }^{1} \mathrm{H}$ NMR $\left(\mathrm{CDCl}_{3}\right) \delta_{\mathrm{H}}(\mathrm{ppm}) 9.28(2 \mathrm{H}, \mathrm{s}, 2 \mathrm{xO}-(\mathrm{C}=\mathrm{O})-(\mathrm{Py}) \mathrm{C}-\mathrm{CH}-\mathrm{N}), 8.60$ $\left(2 \mathrm{H}, \mathrm{d}, 2 \times(\mathrm{Py}) \mathrm{N}-\mathrm{C}-\mathrm{CH}-\mathrm{CH}-\mathrm{C},{ }^{3} J_{\mathrm{H}, \mathrm{H}}=8.2 \mathrm{~Hz}\right), 8.42(2 \mathrm{H}, \mathrm{d}, 2 \times$ (Py) N-C-CH-CH-C, $\left.{ }^{3} \mathrm{~J}_{\mathrm{H}, \mathrm{H}}=8.2 \mathrm{~Hz}\right), 7.10(2 \mathrm{H}, \mathrm{d},(\mathrm{Ar}) \mathrm{CH}-\mathrm{C}-(\mathrm{C}=$ O), $\left.{ }^{3} J_{\mathrm{H}, \mathrm{H}}=8.5 \mathrm{~Hz}\right), 6.81\left(2 \mathrm{H}, \mathrm{d},(\mathrm{Ar}) \mathrm{CH}-\mathrm{C}-\mathrm{O}-\mathrm{CH}_{2}-(\mathrm{C}=\mathrm{O}),{ }^{3} \mathrm{~J}_{\mathrm{H}, \mathrm{H}}=\right.$ $8.5 \mathrm{~Hz}), 5.90\left(2 \mathrm{H}, \mathrm{s}, 2 \times\right.$ cis $\left.(\mathrm{CH}=\mathrm{C})-\mathrm{CH}_{2}-\mathrm{CH}_{3}\right), 5.56(2 \mathrm{H}, \mathrm{s}, 2 \times$ trans $\left.(\mathrm{CH}=\mathrm{C})-\mathrm{CH}_{2}-\mathrm{CH}_{3}\right), 4.82\left(4 \mathrm{H}, \mathrm{s}, 2 \times(\mathrm{Ar}) \mathrm{C}-\mathrm{O}-\mathrm{CH}_{2}-(\mathrm{C}=\right.$ $\mathrm{O})), 4.63\left(8 \mathrm{H}, \mathrm{m}, 2 \times(\mathrm{Ar}) \mathrm{C}-\mathrm{O}-\mathrm{CH}_{2}-(\mathrm{C}=\mathrm{O})-\mathrm{O}-\mathrm{CH}_{2}-\mathrm{CH}_{2}, 2 \times\right.$ (Ar) C-O-CH $\left.-(\mathrm{C}=\mathrm{O})-\mathrm{O}-\mathrm{CH}_{2}-\mathrm{CH}_{2}\right), 2.43\left(4 \mathrm{H}, \mathrm{m}, 2 \times\left(\mathrm{CH}_{2}=\mathrm{C}\right)-\right.$ $\left.\mathrm{CH}_{2}-\mathrm{CH}_{3},{ }^{3} J_{\mathrm{H}, \mathrm{H}}=7.4 \mathrm{~Hz}\right), 1.12\left(6 \mathrm{H}, \mathrm{t}, 2 \times\left(\mathrm{CH}_{2}=\mathrm{C}\right)-\mathrm{CH}_{2}-\mathrm{CH}_{3}\right.$, $\left.{ }^{4} \mathrm{~J}_{\mathrm{H}, \mathrm{H}}=7.4 \mathrm{~Hz}\right) ;{ }^{13} \mathrm{C} \mathrm{NMR}\left(\mathrm{CDCl}_{3}\right) \delta_{\mathrm{C}}(\mathrm{ppm}) 195.8(2 \mathrm{C}, 2 \times(\mathrm{Ar}) \mathrm{C}-$ $\left.(\mathrm{C}=\mathrm{O})-\left(\mathrm{C}=\mathrm{CH}_{2}\right)\right), 167.9\left(2 \mathrm{C}, 2 \times(\mathrm{Ar}) \mathrm{C}-\mathrm{O}-\mathrm{CH}_{2}-(\mathrm{C}=\mathrm{O})\right), 164.9$ $(2 \mathrm{C}, 2 \times(\mathrm{Py}) \mathrm{N}-\mathrm{CH}-\mathrm{C}-(\mathrm{C}=\mathrm{O})-\mathrm{O}), 158.6(2 \mathrm{C}, 2 \times(\mathrm{Py}) \mathrm{N}-\mathrm{C}-\mathrm{CH}-$ CH-C), 155.5 (2C, $2 \times(\mathrm{Ar}) \mathrm{CH}-\mathrm{C}-\mathrm{O}), 150.8(2 \mathrm{C}, 2 \times(\mathrm{Py}) \mathrm{N}-\mathrm{CH}-\mathrm{C}-$ $(\mathrm{C}=\mathrm{O})), 150.3\left(2 \mathrm{C}, 2 \mathrm{xCH}_{3}-\mathrm{CH}_{2}-\left(\mathrm{C}=\mathrm{CH}_{2}\right)\right), 138.4(2 \mathrm{C}, 2 \times(\mathrm{Py}) \mathrm{N}-$ $\mathrm{C}-\mathrm{CH}-\mathrm{CH}-\mathrm{C}), 134.2(2 \mathrm{C}, 2 \times \mathrm{Cl}-(\mathrm{Ar})-\mathrm{C}-\mathrm{C}-(\mathrm{C}=\mathrm{O})), 131.7(2 \mathrm{C}, 2 \times$ Cl-(Ar)-C-C- $(\mathrm{C}=\mathrm{O})), 128.7\left(2 \mathrm{C}, 2 \times\left(\mathrm{CH}_{2}=\mathrm{C}\right)-\mathrm{CH}_{2}-\mathrm{CH}_{3}\right), 126.9$ $(2 \mathrm{C}, 2 \times(\mathrm{Ar}) \mathrm{CH}-\mathrm{C}-(\mathrm{C}=\mathrm{O})), 126.0(2 \mathrm{C}, 2 \times(\mathrm{Py}) \mathrm{N}-\mathrm{CH}-\mathrm{C}-(\mathrm{C}=$ O)-O), $123.6(2 \mathrm{C}, 2 \times \mathrm{Cl}-(\mathrm{Ar}) \mathrm{C}-\mathrm{C}-\mathrm{O}), 121.6(2 \mathrm{C}, 2 \times(\mathrm{Py}) \mathrm{N}-\mathrm{C}-$ $\mathrm{CH}-\mathrm{CH}-\mathrm{C}), 111.0\left(2 \mathrm{C}, 2 \times(\mathrm{Ar}) \mathrm{CH}-\mathrm{C}-\mathrm{O}-\mathrm{CH}_{2}-(\mathrm{C}=\mathrm{O})\right), 66.3(2 \mathrm{C}, 2$ 
$\left.\times(\mathrm{Ar}) \mathrm{C}-\mathrm{O}-\mathrm{CH}_{2}-(\mathrm{C}=\mathrm{O})\right), 63.2\left(2 \mathrm{C}, 2 \times(\mathrm{Ar}) \mathrm{C}-\mathrm{O}-\mathrm{CH}_{2}-(\mathrm{C}=\mathrm{O})-\mathrm{O}-\right.$ $\left.\mathrm{CH}_{2}-\mathrm{CH}_{2}\right), 62.9\left(2 \mathrm{C}, 2 \times(\mathrm{Ar}) \mathrm{C}-\mathrm{O}-\mathrm{CH}_{2}-(\mathrm{C}=\mathrm{O})-\mathrm{O}-\mathrm{CH}_{2}-\mathrm{CH}_{2}\right), 23.5$ $\left(2 \mathrm{C}, 2 \times\left(\mathrm{CH}_{2}=\mathrm{C}\right)-\mathrm{CH}_{2}-\mathrm{CH}_{3}\right), 12.5\left(2 \mathrm{C}, 2 \times\left(\mathrm{CH}_{2}=\mathrm{C}\right)-\mathrm{CH}_{2}-\right.$ $\left.\mathrm{CH}_{3}\right)$; IR $\left(\nu, \mathrm{cm}^{-1}\right) 2967\left(\mathrm{C}-\mathrm{H}, \mathrm{CH}_{2}, \mathrm{CH}_{3}\right), 1762(\mathrm{C}=\mathrm{O}$, ester), $1720(\mathrm{C}=\mathrm{O}$, ester), $1663(\mathrm{C}=\mathrm{O}$, ketone, $\mathrm{C}=\mathrm{C}$, alkene $), 1585$, 1466, 1384 (ring skeleton $\mathrm{C}=\mathrm{C}, \mathrm{C}-\mathrm{C}, \mathrm{C}=\mathrm{N}, \mathrm{C}-\mathrm{N}$ ), 1267, 1190, 1111, 1079 (C-O, ester, ether), 802 (C-H aromatic); ESI-MS $(+) \mathrm{m} /$ $z$ 903.11 $[\mathrm{M}+\mathrm{H}]^{+}, 925.09[\mathrm{M}+\mathrm{Na}]^{+}$, calcd for $\mathrm{C}_{42} \mathrm{H}_{36} \mathrm{Cl}_{4} \mathrm{~N}_{2} \mathrm{O}_{12}$ 902.55 (the isotopic pattern corresponds well to the calculated pattern). Anal. Calcd for $\mathrm{C}_{42} \mathrm{H}_{36} \mathrm{Cl}_{4} \mathrm{~N}_{2} \mathrm{O}_{12}: \mathrm{C}, 55.89 ; \mathrm{H}, 4.02 ; \mathrm{N}, 3.10$. Found: C, 56.00; H, 4.12; N, 3.09 .

General Procedure for the Synthesis of the Ru(II)- and Os(II)Arene Complexes. To a solution of the appropriate dimer, $\left[\mathrm{Ru}\left(\eta^{6}-p\right.\right.$ cymene $) \mathrm{Cl}]_{2} \mathrm{Cl}_{2}$ or $\left[\mathrm{Os}\left(\eta^{6}-p\right.\right.$-cymene $) \mathrm{Cl}_{2} \mathrm{Cl}_{2}$, in $\mathrm{CH}_{2} \mathrm{Cl}_{2}(10 \mathrm{~mL})$ was added a solution of the appropriate ligand in $\mathrm{CH}_{2} \mathrm{Cl}_{2}(25 \mathrm{~mL})$, and the obtained mixture was stirred at room temperature in the dark for $24 \mathrm{~h}$. The solvent was removed under reduced pressure, the crude product was redissolved in $\mathrm{CH}_{2} \mathrm{Cl}_{2}(1 \mathrm{~mL})$, and the product was precipitated with $\mathrm{Et}_{2} \mathrm{O}(5 \mathrm{~mL})$ and then successively washed with warm $\mathrm{Et}_{2} \mathrm{O}(4 \times$ $50 \mathrm{~mL})$ and hexane $(2 \times 25 \mathrm{~mL})$. The resulting solid was dried under high vacuum.

Synthesis of $\left[R u\left(\eta^{6}-p\right.\right.$-cymene $\left.) C I\right]\left[\left(4^{\prime}\right.\right.$-methyl-[2,2'-bipyridin]-4yl)methyl-2-(2,3-dichloro-4-(2-ethylenebutanoyl)phenoxy)acetate]$\mathrm{Cl}$ (1a). Complex 1a was prepared following the general procedure starting from $\left[\mathrm{Ru}\left(\eta^{6}-p\right.\right.$-cymene $) \mathrm{Cl}_{2} \mathrm{Cl}_{2}(0.222 \mathrm{~g}, 1$ equiv) and ligand L1 $(0.352 \mathrm{~g}, 2$ equiv), to afford an orange solid $(0.537 \mathrm{~g}$, yield $94 \%)$ : mp $\left({ }^{\circ} \mathrm{C}\right) 149-151 \mathrm{dec} ;{ }^{1} \mathrm{H}$ NMR $\left(\mathrm{MeOD}-d_{4}\right) \delta_{\mathrm{H}}(\mathrm{ppm}) 9.41(1 \mathrm{H}, \mathrm{d}$, $\left.\mathrm{O}-\mathrm{CH}_{2}-(\mathrm{Py}) \mathrm{C}-\mathrm{CH}-\mathrm{CH}-\mathrm{N},{ }^{3} \mathrm{~J}_{\mathrm{H}, \mathrm{H}}=5.9 \mathrm{~Hz}\right), 9.28\left(1 \mathrm{H}, \mathrm{d}, \mathrm{CH}_{3}-(\mathrm{Py}) \mathrm{C}-\right.$ $\left.\mathrm{CH}-\mathrm{CH}-\mathrm{N},{ }^{3} \mathrm{~J}_{\mathrm{H}, \mathrm{H}}=5.9 \mathrm{~Hz}\right), 8.46\left(1 \mathrm{H}, \mathrm{m}, \mathrm{O}-\mathrm{CH}_{2}-(\mathrm{Py}) \mathrm{C}-\mathrm{CH}-\mathrm{C}-\mathrm{N}\right)$, $8.39\left(1 \mathrm{H}, \mathrm{m}, \mathrm{CH}_{3}-(\mathrm{Py}) \mathrm{C}-\mathrm{CH}-\mathrm{C}-\mathrm{N}\right), 7.61\left(1 \mathrm{H}, \mathrm{dd}, \mathrm{O}-\mathrm{CH}_{2}-(\mathrm{Py}) \mathrm{C}-\mathrm{CH}-\right.$ $\left.\mathrm{CH}-\mathrm{N},{ }^{3} J_{\mathrm{H}, \mathrm{H}}=5.9 \mathrm{~Hz},{ }^{4} \mathrm{~J}_{\mathrm{H}, \mathrm{H}}=1.1 \mathrm{~Hz}\right), 7.59\left(1 \mathrm{H}, \mathrm{dd}, \mathrm{CH}_{3}-(\mathrm{Py}) \mathrm{C}-\mathrm{CH}-\right.$ $\left.\mathrm{CH}-\mathrm{N},{ }^{3} J_{\mathrm{H}, \mathrm{H}}=5.9 \mathrm{~Hz},{ }^{4} \mathrm{~J}_{\mathrm{H}, \mathrm{H}}=1.7 \mathrm{~Hz}\right), 7.21(1 \mathrm{H}, \mathrm{d},(\mathrm{Ar}) \mathrm{CH}-\mathrm{C}-(\mathrm{C}=$ O), $\left.{ }^{3} \mathrm{~J}_{\mathrm{H}, \mathrm{H}}=8.6 \mathrm{~Hz}\right), 7.11\left(1 \mathrm{H}, \mathrm{d},(\mathrm{Ar}) \mathrm{CH}-\mathrm{C}-\mathrm{O}-\mathrm{CH}_{2}-(\mathrm{C}=\mathrm{O}),{ }^{3} \mathrm{~J}_{\mathrm{H}, \mathrm{H}}=\right.$ $8.6 \mathrm{~Hz}), 6.09-6.11\left(2 \mathrm{H}, \mathrm{m}, 2 \mathrm{xCH}_{3}-(\mathrm{Ar}) \mathrm{C}-\mathrm{CH}-\mathrm{CH}-\mathrm{C}\right), 6.04(1 \mathrm{H}, \mathrm{t}$, cis $\left.(\mathrm{CH}=\mathrm{C})-\mathrm{CH}_{2}-\mathrm{CH}_{3},{ }^{4} J_{\mathrm{H}, \mathrm{H}}=1.3 \mathrm{~Hz}\right), 5.86\left(1 \mathrm{H}, \mathrm{m}, \mathrm{CH}_{3}-(\mathrm{Ar}) \mathrm{C}-\mathrm{CH}-\right.$ $\left.\mathrm{CH}-\mathrm{C},{ }^{3} J_{\mathrm{H}, \mathrm{H}}=8.5 \mathrm{~Hz}\right), 5.84\left(1 \mathrm{H}, \mathrm{m}, \mathrm{CH}_{3}-(\mathrm{Ar}) \mathrm{C}-\mathrm{CH}-\mathrm{CH}-\mathrm{C},{ }^{3} \mathrm{~J}_{\mathrm{H}, \mathrm{H}}=\right.$ $8.5 \mathrm{~Hz}), 5.59\left(1 \mathrm{H}\right.$, s, trans $\left.(\mathrm{CH}=\mathrm{C})-\mathrm{CH}_{2}-\mathrm{CH}_{3}\right), 5.51\left(2 \mathrm{H}, \mathrm{s}, \mathrm{O}-\mathrm{CH}_{2}-\right.$ (Py)C-CH-CH-N), $5.14\left(2 \mathrm{H}, \mathrm{s},(\mathrm{Ar}) \mathrm{C}-\mathrm{O}-\mathrm{CH}_{2}-(\mathrm{C}=\mathrm{O})\right), 2.63(3 \mathrm{H}, \mathrm{s}$, $\mathrm{CH}_{3}$-(Py)C-CH-CH-N), 2.62 (1H, sept, (Ar)C-CH-CH-C$\left.\mathrm{CH}\left(\mathrm{CH}_{3}\right)_{2},{ }^{3} J_{\mathrm{H}, \mathrm{H}}=6.9 \mathrm{~Hz}\right), 2.45\left(2 \mathrm{H}, \mathrm{m},\left(\mathrm{CH}_{2}=\mathrm{C}\right)-\mathrm{CH}_{2}-\mathrm{CH}_{3}\right.$, $\left.{ }^{3} J_{\mathrm{H}, \mathrm{H}}=7.4 \mathrm{~Hz}\right), 2.26\left(3 \mathrm{H}, \mathrm{s}, \mathrm{CH}_{3}-(\mathrm{Ar}) \mathrm{C}-\mathrm{CH}-\mathrm{CH}-\mathrm{C}\right), 1.15(3 \mathrm{H}, \mathrm{t}$, $\left.\left(\mathrm{CH}_{2}=\mathrm{C}\right)-\mathrm{CH}_{2}-\mathrm{CH}_{3},{ }^{4} \mathrm{~J}_{\mathrm{H}, \mathrm{H}}=7.4 \mathrm{~Hz}\right), 1.04(3 \mathrm{H}, \mathrm{d},(\mathrm{Ar}) \mathrm{C}-\mathrm{CH}-\mathrm{CH}-\mathrm{C}-$ $\left.\mathrm{CH}-\mathrm{CH}_{3},{ }^{3} \mathrm{~J}_{\mathrm{H}, \mathrm{H}}=6.9 \mathrm{~Hz}\right), 1.02\left(3 \mathrm{H}, \mathrm{d},(\mathrm{Ar}) \mathrm{C}-\mathrm{CH}-\mathrm{CH}-\mathrm{C}-\mathrm{CH}-\mathrm{CH}_{3}\right.$, $\left.{ }^{3} J_{\mathrm{H}, \mathrm{H}}=6.9 \mathrm{~Hz}\right) ;{ }^{13} \mathrm{C}$ NMR $\left(\mathrm{MeOD}-d_{4}\right) \delta_{\mathrm{C}}(\mathrm{ppm}) 197.3(1 \mathrm{C},(\mathrm{Ar}) \mathrm{C}-$ $\left.(\mathrm{C}=\mathrm{O})-\left(\mathrm{C}=\mathrm{CH}_{2}\right)\right), 169.1\left(\mathrm{C},(\mathrm{Ar}) \mathrm{C}-\mathrm{O}-\mathrm{CH}_{2}-(\mathrm{C}=\mathrm{O})\right), 157.0(1 \mathrm{C}$, $\left.\mathrm{O}-\mathrm{CH}_{2}-(\mathrm{Py}) \mathrm{C}-\mathrm{CH}-\mathrm{C}-\mathrm{N}\right), \quad 156.7$ (1C, O-CH $\left.-(\mathrm{Py}) \mathrm{C}-\mathrm{CH}-\mathrm{CH}-\mathrm{N}\right)$, 156.5 (1C, (Ar)CH-C-O-CH $\left.{ }_{2}(\mathrm{C}=\mathrm{O})\right), 156.1$ (1C, $\mathrm{CH}_{3}-(\mathrm{Py}) \mathrm{C}-$ CH-CH-N), 155.5 (1C, $\left.\mathrm{CH}_{3}-(\mathrm{Py}) \mathrm{C}-\mathrm{CH}-\mathrm{C}-\mathrm{N}\right), 154.2\left(1 \mathrm{C}, \mathrm{CH}_{3}-\mathrm{CH}_{2}-\right.$ $\left.\left(\mathrm{C}=\mathrm{CH}_{2}\right)\right), 151.6\left(1 \mathrm{C}, \mathrm{O}-\mathrm{CH}_{2}-(\mathrm{Py}) \mathrm{C}-\mathrm{CH}-\mathrm{CH}-\mathrm{N}\right), 151.1\left(1 \mathrm{C}, \mathrm{CH}_{3}-\right.$ (Py)C-CH-CH-N), 134.9 (1C, Cl- $(\mathrm{Ar}) \mathrm{C}-\mathrm{C}-(\mathrm{C}=\mathrm{O})), 131.9$ (1C, Cl(Ar)-C-C- $(\mathrm{C}=\mathrm{O})), 130.1 \quad\left(1 \mathrm{C},\left(\mathrm{CH}_{2}=\mathrm{C}\right)-\mathrm{CH}_{2}-\mathrm{CH}_{3}\right), 129.9$ (1C, $(\mathrm{Ar}) \mathrm{CH}-\mathrm{C}-(\mathrm{C}=\mathrm{O})), 128.4\left(1 \mathrm{C}, \mathrm{CH}_{3}-(\mathrm{Py}) \mathrm{C}-\mathrm{CH}-\mathrm{CH}-\mathrm{N}\right), 126.5$ (1C, $\left.\mathrm{CH}_{3}-(\mathrm{Py}) \mathrm{C}-\mathrm{CH}-\mathrm{C}-\mathrm{N}\right), 125.9$ (1C, O-CH $\left.-(\mathrm{Py}) \mathrm{C}-\mathrm{CH}-\mathrm{CH}-\mathrm{N}\right), 123.8$ (1C, Cl-(Ar)C-C-O), 122.7 (1C, O-CH $\left.{ }_{2}-(\mathrm{Py}) \mathrm{C}-\mathrm{CH}-\mathrm{C}-\mathrm{N}\right), 112.6$ (1C, (Ar) $\left.\mathrm{CH}-\mathrm{C}-\mathrm{O}-\mathrm{CH}_{2}-(\mathrm{C}=\mathrm{O})\right), 105.8 \quad\left(1 \mathrm{C}, \mathrm{CH}_{3}-(\mathrm{Ar}) \mathrm{C}-\mathrm{CH}-\mathrm{CH}-\mathrm{C}\right)$, $105.6\left(1 \mathrm{C}, \mathrm{CH}_{3}-(\mathrm{Ar}) \mathrm{C}-\mathrm{CH}-\mathrm{CH}-\mathrm{C}\right), 88.2\left(1 \mathrm{C}, \mathrm{CH}_{3}-(\mathrm{Ar}) \mathrm{C}-\mathrm{CH}-\mathrm{CH}-\right.$ C), 88.0 (1C, $\left.\mathrm{CH}_{3}-(\mathrm{Ar}) \mathrm{C}-\mathrm{CH}-\mathrm{CH}-\mathrm{C}\right), 85.5$ (1C, $\mathrm{CH}_{3}-(\mathrm{Ar}) \mathrm{C}-\mathrm{CH}-\mathrm{CH}-$ C), $85.3\left(1 \mathrm{C}, \mathrm{CH}_{3}-(\mathrm{Ar}) \mathrm{C}-\mathrm{CH}-\mathrm{CH}-\mathrm{C}\right), 67.1$ (1C, $(\mathrm{Ar}) \mathrm{C}-\mathrm{O}-\mathrm{CH}_{2}-(\mathrm{C}=$ $\mathrm{O})$ ), 65.2 (1C, O-CH ${ }_{2}$ (Py)C-CH-CH-N), 32.3 (1C, (Ar)CH-CH-C$\left.\mathrm{CH}\left(\mathrm{CH}_{3}\right)_{2}\right), 24.5\left(1 \mathrm{C},\left(\mathrm{CH}_{2}=\mathrm{C}\right)-\mathrm{CH}_{2}-\mathrm{CH}_{3}\right), 22.3(2 \mathrm{C},(\mathrm{Ar}) \mathrm{CH}-\mathrm{CH}-$ $\left.\mathrm{C}-\mathrm{CH}\left(\mathrm{CH}_{3}\right)_{2}\right), 21.3$ (1C, $\left.\mathrm{CH}_{3}-(\mathrm{Py}) \mathrm{C}-\mathrm{CH}-\mathrm{CH}-\mathrm{N}\right), 19.0$ (1C, $\mathrm{CH}_{3}-$ (Ar)C-CH-CH-C), $13.0\left(1 \mathrm{C},\left(\mathrm{CH}_{2}=\mathrm{C}\right)-\mathrm{CH}_{2}-\mathrm{CH}_{3}\right) ; \mathrm{IR}\left(\nu, \mathrm{cm}^{-1}\right)$ 3060-2872 (C-H, $\left.\mathrm{CH}_{2}, \mathrm{CH}_{3}\right), 1763(\mathrm{C}=\mathrm{O}$, ester), 1661, 1620 $(\mathrm{C}=\mathrm{O}$, ketone, $\mathrm{C}=\mathrm{C}$, alkene), $1580,1470,1384$ (ring skeleton $\mathrm{C}=$ $\mathrm{C}, \mathrm{C}-\mathrm{C}, \mathrm{C}=\mathrm{N}, \mathrm{C}-\mathrm{N}), 1284,1210,1075$ (C-O, ester, ether), 800 (C-H aromatic); ESI-MS(+): $m / z 756.06[\mathrm{M}-\mathrm{Cl}]^{+}$, calcd for $\mathrm{C}_{35} \mathrm{H}_{36} \mathrm{Cl}_{3} \mathrm{~N}_{2} \mathrm{O}_{4} \mathrm{Ru}^{+} 756.10$ (the isotopic pattern corresponds well to the calculated pattern). Anal. Calcd for $\mathrm{C}_{35} \mathrm{H}_{36} \mathrm{Cl}_{4} \mathrm{~N}_{2} \mathrm{O}_{4} \mathrm{Ru}$ : C, 53.11; H, 4.58; N, 3.54. Found: C, 53.16; H, 4.58; N, 3.34.
Synthesis of $\left[\mathrm{Os}\left(\eta^{6}\right.\right.$-p-cymene $\left.) \mathrm{Cl}\right]\left[\left(4^{\prime}-\right.\right.$-methyl-[2,2'-bipyridin]-4yl)methyl-2-(2,3-dichloro-4-(2-ethylenebutanoyl)phenoxy)acetate]$\mathrm{Cl}(\mathbf{1 b})$. Complex $1 \mathrm{~b}$ was prepared following the general procedure starting from $\left[\mathrm{Os}\left(\eta^{6}-p\right.\right.$-cymene $) \mathrm{Cl}_{2} \mathrm{Cl}_{2}(0.291 \mathrm{~g}, 1$ equiv) and ligand L1 $(0.357 \mathrm{~g}$, 1 equiv), to afford a yellow solid $(0.597 \mathrm{~g}$, yield $92 \%): \mathrm{mp}$ $\left({ }^{\circ} \mathrm{C}\right): 159-161 \mathrm{dec} ;{ }^{1} \mathrm{H}$ NMR $\left(\mathrm{MeOD}-d_{4}\right) \delta_{\mathrm{H}}(\mathrm{ppm}) 9.34(1 \mathrm{H}, \mathrm{d}, \mathrm{O}-$ $\left.\mathrm{CH}_{2}-(\mathrm{Py}) \mathrm{C}-\mathrm{CH}-\mathrm{CH}-\mathrm{N},{ }^{3} \mathrm{~J}_{\mathrm{H}, \mathrm{H}}=6.0 \mathrm{~Hz}\right), 9.22\left(1 \mathrm{H}, \mathrm{d}, \mathrm{CH}_{3}-(\mathrm{Py}) \mathrm{C}-\mathrm{CH}-\right.$ $\left.\mathrm{CH}-\mathrm{N},{ }^{3} J_{\mathrm{H}, \mathrm{H}}=5.9 \mathrm{~Hz}\right), 8.56\left(1 \mathrm{H}, \mathrm{m}, \mathrm{O}-\mathrm{CH}_{2}-(\mathrm{Py}) \mathrm{C}-\mathrm{CH}-\mathrm{C}-\mathrm{N}\right), 8.48$ $\left(1 \mathrm{H}, \mathrm{m}, \mathrm{CH}_{3}-(\mathrm{Py}) \mathrm{C}-\mathrm{CH}-\mathrm{C}-\mathrm{N}\right), 7.58\left(\mathrm{H}, \mathrm{dd}, \mathrm{O}-\mathrm{CH}_{2}-(\mathrm{Py}) \mathrm{C}-\mathrm{CH}-\mathrm{CH}-\right.$ $\left.\mathrm{N},{ }^{3} J_{\mathrm{H}, \mathrm{H}}=6.0 \mathrm{~Hz},{ }^{4} J_{\mathrm{H}, \mathrm{H}}=1.4 \mathrm{~Hz}\right), 7.56\left(1 \mathrm{H}, \mathrm{dd}, \mathrm{CH}_{3}-(\mathrm{Py}) \mathrm{C}-\mathrm{CH}-\mathrm{CH}-\right.$ $\left.\mathrm{N},{ }^{3} \mathrm{~J}_{\mathrm{H}, \mathrm{H}}=5.9 \mathrm{~Hz},{ }^{4} \mathrm{~J}_{\mathrm{H}, \mathrm{H}}=1.9 \mathrm{~Hz}\right), 7.21(1 \mathrm{H}, \mathrm{d},(\mathrm{Ar}) \mathrm{CH}-\mathrm{C}-(\mathrm{C}=\mathrm{O})$, $\left.{ }^{3} \mathrm{~J}_{\mathrm{H}, \mathrm{H}}=8.6 \mathrm{~Hz}\right), 7.11\left(1 \mathrm{H}, \mathrm{d},(\mathrm{Ar}) \mathrm{CH}-\mathrm{C}-\mathrm{O}-\mathrm{CH}_{2}-(\mathrm{C}=\mathrm{O}),{ }^{3} \mathrm{~J}_{\mathrm{H}, \mathrm{H}}=8.6\right.$ $\mathrm{Hz}), 6.32\left(1 \mathrm{H}, \mathrm{m}, \mathrm{CH}_{3}-(\mathrm{Ar}) \mathrm{C}-\mathrm{CH}-\mathrm{CH}-\mathrm{C}\right), 6.30\left(1 \mathrm{H}, \mathrm{m}, \mathrm{CH}_{3}-(\mathrm{Ar}) \mathrm{C}-\right.$ $\mathrm{CH}-\mathrm{CH}-\mathrm{C}), 6.04\left(1 \mathrm{H}, \mathrm{t}\right.$, cis $\left.(\mathrm{CH}=\mathrm{C})-\mathrm{CH}_{2}-\mathrm{CH}_{3},{ }^{4} J_{\mathrm{H}, \mathrm{H}}=0.9 \mathrm{~Hz}\right), 6.01$ $\left(1 \mathrm{H}, \mathrm{d}, \mathrm{CH}_{3}-(\mathrm{Ar}) \mathrm{C}-\mathrm{CH}-\mathrm{CH}-\mathrm{C},{ }^{3} J_{\mathrm{H}, \mathrm{H}}=6.2 \mathrm{~Hz}\right), 5.99\left(1 \mathrm{H}, \mathrm{d}, \mathrm{CH}_{3}-\right.$ (Ar)C-CH-CH-C, $\left.{ }^{3} J_{\mathrm{H}, \mathrm{H}}=6.2 \mathrm{~Hz}\right), 5.59\left(1 \mathrm{H}, \mathrm{s}\right.$, trans $(\mathrm{CH}=\mathrm{C})-\mathrm{CH}_{2}-$ $\left.\mathrm{CH}_{3}\right), 5.56\left(2 \mathrm{H}, \mathrm{s}, \mathrm{O}-\mathrm{CH}_{2}-(\mathrm{Py}) \mathrm{C}-\mathrm{CH}-\mathrm{CH}-\mathrm{N}\right), 5.14(2 \mathrm{H}, \mathrm{s},(\mathrm{Ar}) \mathrm{C}-\mathrm{O}-$ $\left.\mathrm{CH}_{2}-(\mathrm{C}=\mathrm{O})\right), 2.70\left(3 \mathrm{H}, \mathrm{s}, \mathrm{CH}_{3}-(\mathrm{Py}) \mathrm{C}-\mathrm{CH}-\mathrm{CH}-\mathrm{N}\right), 2.48(1 \mathrm{H}$, sept, (Ar)C-CH-CH-C-CH( $\left.\left(\mathrm{CH}_{3}\right)_{2},{ }^{3} \mathrm{~J}_{\mathrm{H}, \mathrm{H}}=6.9 \mathrm{~Hz}\right), 2.45\left(2 \mathrm{H}, \mathrm{m},\left(\mathrm{CH}_{2}=\right.\right.$ C) $\left.-\mathrm{CH}_{2}-\mathrm{CH}_{3},{ }^{3} J_{\mathrm{H}, \mathrm{H}}=7.4 \mathrm{~Hz}\right), 2.33\left(3 \mathrm{H}, \mathrm{s}, \mathrm{CH}_{3}\right.$-( Ar)C-CH-CH-C), $1.15\left(3 \mathrm{H}, \mathrm{t},\left(\mathrm{CH}_{2}=\mathrm{C}\right)-\mathrm{CH}_{2}-\mathrm{CH}_{3},{ }^{4} J_{\mathrm{H}, \mathrm{H}}=7.4 \mathrm{~Hz}\right), 0.98(3 \mathrm{H}, \mathrm{d}$, (Ar)C-CH-CH-C-CH-CH,$\left.{ }_{3}^{3} J_{\mathrm{H}, \mathrm{H}}=6.9 \mathrm{~Hz}\right), 0.97(3 \mathrm{H}, \mathrm{d},(\mathrm{Ar}) \mathrm{C}-\mathrm{CH}-$ $\left.\mathrm{CH}-\mathrm{C}-\mathrm{CH}-\mathrm{CH}_{3},{ }^{3} J_{\mathrm{H}, \mathrm{H}}=6.9 \mathrm{~Hz}\right) ;{ }^{13} \mathrm{C}$ NMR $\left(\mathrm{MeOD}-d_{4}\right) \delta_{\mathrm{C}}(\mathrm{ppm})$ $197.3\left(1 \mathrm{C},(\mathrm{Ar}) \mathrm{C}-(\mathrm{C}=\mathrm{O})-\left(\mathrm{C}=\mathrm{CH}_{2}\right)\right), 169.1 \quad\left(\mathrm{C},(\mathrm{Ar}) \mathrm{C}-\mathrm{O}-\mathrm{CH}_{2}-\right.$ $(\mathrm{C}=\mathrm{O})), 157.4\left(1 \mathrm{C}, \mathrm{O}-\mathrm{CH}_{2}-(\mathrm{Py}) \mathrm{C}-\mathrm{CH}-\mathrm{C}-\mathrm{N}\right), 157.0 \quad\left(1 \mathrm{C}, \mathrm{CH}_{3}-\right.$ (Py)C-CH-C-N), 156.6 (1C, O-CH $-(\mathrm{Py}) \mathrm{C}-\mathrm{CH}-\mathrm{CH}-\mathrm{N}), 156.3$ (1C, (Ar) CH-C-O- $\left.\mathrm{CH}_{2}-(\mathrm{C}=\mathrm{O})\right), 156.0$ (1C, $\left.\mathrm{CH}_{3}-(\mathrm{Py}) \mathrm{C}-\mathrm{CH}-\mathrm{CH}-\mathrm{N}\right)$, $154.3\left(1 \mathrm{C}, \mathrm{CH}_{3}-\mathrm{CH}_{2}-\left(\mathrm{C}=\mathrm{CH}_{2}\right)\right), 151.7 \quad\left(1 \mathrm{C}, \mathrm{O}-\mathrm{CH}_{2}-(\mathrm{Py}) \mathrm{C}-\mathrm{CH}-\right.$ $\mathrm{CH}-\mathrm{N}), 151.0$ (1C, $\left.\mathrm{CH}_{3}-(\mathrm{Py}) \mathrm{C}-\mathrm{CH}-\mathrm{CH}-\mathrm{N}\right), 134.9$ (1C, Cl-(Ar)C-C$(\mathrm{C}=\mathrm{O})), 131.9(1 \mathrm{C}, \mathrm{Cl}-(\mathrm{Ar}) \mathrm{C}-\mathrm{C}-(\mathrm{C}=\mathrm{O})), 130.6\left(1 \mathrm{C},\left(\mathrm{CH}_{2}=\mathrm{C}\right)-\right.$ $\left.\mathrm{CH}_{2}-\mathrm{CH}_{3}\right), 130.1(1 \mathrm{C},(\mathrm{Ar}) \mathrm{CH}-\mathrm{C}-(\mathrm{C}=\mathrm{O})), 128.4\left(1 \mathrm{C}, \mathrm{CH}_{3}-(\mathrm{Py}) \mathrm{C}-\right.$ $\mathrm{CH}-\mathrm{CH}-\mathrm{N}), 127.3$ (1C, $\left.\mathrm{CH}_{3}-(\mathrm{Py}) \mathrm{C}-\mathrm{CH}-\mathrm{C}-\mathrm{N}\right), 125.9$ (1C, O-CH (Py)C-CH-CH-N), 123.8 (1C, Cl-(Ar)C-C-O), 122.9 (1C, O- $\mathrm{CH}_{2}-$ (Py)C-CH-C-N), $112.6\left(1 \mathrm{C},(\mathrm{Ar}) \mathrm{CH}-\mathrm{C}-\mathrm{O}-\mathrm{CH}_{2}-(\mathrm{C}=\mathrm{O})\right), 98.8$ (1C, $\mathrm{CH}_{3}$-(Ar)C-CH-CH-C), 96.6 (1C, $\left.\mathrm{CH}_{3}-(\mathrm{Ar}) \mathrm{C}-\mathrm{CH}-\mathrm{CH}-\mathrm{C}\right), 79.6$ (1C, $\left.\mathrm{CH}_{3}-(\mathrm{Ar}) \mathrm{C}-\mathrm{CH}-\mathrm{CH}-\mathrm{C}\right), 79.5$ (1C, $\left.\mathrm{CH}_{3}-(\mathrm{Ar}) \mathrm{C}-\mathrm{CH}-\mathrm{CH}-\mathrm{C}\right), 75.4$ (1C, $\left.\mathrm{CH}_{3}-(\mathrm{Ar}) \mathrm{C}-\mathrm{CH}-\mathrm{CH}-\mathrm{C}\right), 75.2$ (1C, $\left.\mathrm{CH}_{3}-(\mathrm{Ar}) \mathrm{C}-\mathrm{CH}-\mathrm{CH}-\mathrm{C}\right), 67.1$ (1C, (Ar)C-O- $\mathrm{CH}_{2}-(\mathrm{C}=\mathrm{O})$ ), $65.2\left(1 \mathrm{C}, \mathrm{O}-\mathrm{CH}_{2}-(\mathrm{Py}) \mathrm{C}-\mathrm{CH}-\mathrm{CH}-\mathrm{N}\right), 32.6$ $\left(1 \mathrm{C},(\mathrm{Ar}) \mathrm{CH}-\mathrm{CH}-\mathrm{C}-\mathrm{CH}\left(\mathrm{CH}_{3}\right)_{2}\right), 24.5\left(1 \mathrm{C},\left(\mathrm{CH}_{2}=\mathrm{C}\right)-\mathrm{CH}_{2}-\mathrm{CH}_{3}\right)$, 22.6 (2C, $\left.(\mathrm{Ar}) \mathrm{CH}-\mathrm{CH}-\mathrm{C}-\mathrm{CH}\left(\mathrm{CH}_{3}\right)_{2}\right), 21.3\left(1 \mathrm{C}, \mathrm{CH}_{3}-(\mathrm{Py}) \mathrm{C}-\mathrm{CH}-\mathrm{CH}-\right.$ $\mathrm{N}), 18.9\left(1 \mathrm{C}, \mathrm{CH}_{3}-(\mathrm{Ar}) \mathrm{C}-\mathrm{CH}-\mathrm{CH}-\mathrm{C}\right), 13.0\left(1 \mathrm{C},\left(\mathrm{CH}_{2}=\mathrm{C}\right)-\mathrm{CH}_{2}\right.$ $\left.\mathrm{CH}_{3}\right)$; IR $\left(\nu, \mathrm{cm}^{-1}\right)$ 2961-2924 $\left(\mathrm{C}-\mathrm{H}, \mathrm{CH}_{2}, \mathrm{CH}_{3}\right), 1762(\mathrm{C}=\mathrm{O}$, ester), 1663, $1621(\mathrm{C}=\mathrm{O}$, ketone, $\mathrm{C}=\mathrm{C}$, alkene $), 1580,1468,1382$ (ring skeleton $\mathrm{C}=\mathrm{C}, \mathrm{C}-\mathrm{C}, \mathrm{C}=\mathrm{N}, \mathrm{C}-\mathrm{N}), 1283,1195,1074(\mathrm{C}-\mathrm{O}$, ester, ether), 801 (C-H aromatic); ESI-MS(+) $\mathrm{m} / z$ 845.11 [M $\mathrm{Cl}]^{+}$, calcd for $\mathrm{C}_{35} \mathrm{H}_{36} \mathrm{Cl}_{3} \mathrm{~N}_{2} \mathrm{O}_{4} \mathrm{Os}^{+} 845.26$ (the isotopic pattern corresponds well to the calculated pattern). Anal. Calcd for $\mathrm{C}_{35} \mathrm{H}_{36} \mathrm{Cl}_{4} \mathrm{~N}_{2} \mathrm{O}_{4} \mathrm{Os}$ : C, 47.73; $\mathrm{H}, 4.12 ; \mathrm{N}, 3.18$. Found: $\mathrm{C}, 47.93 ; \mathrm{H}$, 4.12; N, 2.99.

Synthesis of $\left[R u\left(\eta^{6}-p\right.\right.$-cymene)Cl][bis(2-(2-(2,3-dichloro-4-(2methylenebutanoyl)phenoxy)acetoxy)ethyl)-(2,2'-bipyridine)-5, $5^{\prime}$ dicarboxylate]Cl (2a). Complex 2 a was prepared following the general procedure starting from $\left[\mathrm{Ru}\left(\eta^{6}-p \text {-cymene }\right) \mathrm{Cl}_{2}\right]_{2} \mathrm{Cl}_{2}(0.085 \mathrm{~g}, 1$ equiv) and ligand $\mathbf{L} 2(0.250 \mathrm{~g}, 2$ equiv), to afford a yellow solid $(0.263 \mathrm{~g}$, yield 79\%): mp ( $\left.{ }^{\circ} \mathrm{C}\right): 97-99 ;{ }^{1} \mathrm{H}$ NMR $\left(\mathrm{CDCl}_{3}\right) \delta_{\mathrm{H}}(\mathrm{ppm}) 9.75(2 \mathrm{H}, \mathrm{s}, 2 \times$ $\mathrm{O}-(\mathrm{C}=\mathrm{O})-(\mathrm{Py}) \mathrm{C}-\mathrm{CH}-\mathrm{N}), 9.27(2 \mathrm{H}, \mathrm{d}, 2 \times(\mathrm{Py}) \mathrm{N}-\mathrm{C}-\mathrm{CH}-\mathrm{CH}-\mathrm{C}$, $\left.{ }^{3} J_{\mathrm{H}, \mathrm{H}}=7.8 \mathrm{~Hz}\right), 8.59\left(2 \mathrm{H}, \mathrm{d}, 2 \times(\mathrm{Py}) \mathrm{N}-\mathrm{C}-\mathrm{CH}-\mathrm{CH}-\mathrm{C},{ }^{3} J_{\mathrm{H}, \mathrm{H}}=7.8\right.$ $\mathrm{Hz}), 7.11\left(2 \mathrm{H}, \mathrm{d}, 2 \times(\mathrm{Ar}) \mathrm{CH}-\mathrm{C}-(\mathrm{C}=\mathrm{O}),{ }^{3} J_{\mathrm{H}, \mathrm{H}}=8.4 \mathrm{~Hz}\right), 6.93(2 \mathrm{H}$, d, $\left.2 \times(\mathrm{Ar}) \mathrm{CH}-\mathrm{C}-\mathrm{O}-\mathrm{CH}_{2}-(\mathrm{C}=\mathrm{O}),{ }^{3} J_{\mathrm{H} H}=8.4 \mathrm{~Hz}\right), 6.15(2 \mathrm{H}, \mathrm{d}$, $\left.2 \mathrm{xCH}_{3}-(\mathrm{Ar}) \mathrm{C}-\mathrm{CH}-\mathrm{CH}-\mathrm{C},{ }^{3} J_{\mathrm{H}, \mathrm{H}}=5.4 \mathrm{~Hz}\right), 6.01\left(2 \mathrm{H}, \mathrm{d}, 2 \times \mathrm{CH}_{3}-\right.$ (Ar)C-CH-CH-C, $\left.{ }^{3} J_{\mathrm{H}, \mathrm{H}}=5.4 \mathrm{~Hz}\right), 5.92(2 \mathrm{H}, \mathrm{s}, 2 \times$ cis $(\mathrm{CH}=\mathrm{C})-$ $\left.\mathrm{CH}_{2}-\mathrm{CH}_{3}\right), 5.55\left(2 \mathrm{H}, \mathrm{s}, 2 \times\right.$ trans $\left.(\mathrm{CH}=\mathrm{C})-\mathrm{CH}_{2}-\mathrm{CH}_{3}\right), 5.02(2 \mathrm{H}, \mathrm{d}$, $\left.2 \times(\mathrm{Ar}) \mathrm{C}-\mathrm{O}-\mathrm{CH}-(\mathrm{C}=\mathrm{O})-\mathrm{O}-\left(\mathrm{CH}_{2}\right)_{2}-\mathrm{O},{ }^{1} J_{\mathrm{H}, \mathrm{H}}=17.7 \mathrm{~Hz}\right), 4.91(2 \mathrm{H}$, d, $\left.2 \times(\mathrm{Ar}) \mathrm{C}-\mathrm{O}-\mathrm{CH}-(\mathrm{C}=\mathrm{O})-\mathrm{O}-\left(\mathrm{CH}_{2}\right)_{2}-\mathrm{O},{ }^{1} \mathrm{~J}_{\mathrm{H}, \mathrm{H}}=17.7 \mathrm{~Hz}\right), 4.54-$ $4.83\left(8 \mathrm{H}, \mathrm{m}, 2 \times(\mathrm{Ar}) \mathrm{C}-\mathrm{O}-\mathrm{CH}_{2}-(\mathrm{C}=\mathrm{O})-\mathrm{O}-\mathrm{CH}_{2}-\mathrm{CH}_{2}, 2 \times(\mathrm{Ar}) \mathrm{C}-\mathrm{O}-\right.$ $\left.\mathrm{CH}_{2}-(\mathrm{C}=\mathrm{O})-\mathrm{O}-\mathrm{CH}_{2}-\mathrm{CH}_{2}\right), 2.75(1 \mathrm{H}$, sept, $(\mathrm{Ar}) \mathrm{C}-\mathrm{CH}-\mathrm{CH}-\mathrm{C}-$ $\left.\mathrm{CH}\left(\mathrm{CH}_{3}\right)_{2},{ }^{3} J_{\mathrm{H}, \mathrm{H}}=6.7 \mathrm{~Hz}\right), 2.42\left(4 \mathrm{H}, \mathrm{m}, 2 \times\left(\mathrm{CH}_{2}=\mathrm{C}\right)-\mathrm{CH}_{2}-\right.$ $\left.\mathrm{CH}_{3},{ }^{3} J_{\mathrm{H}, \mathrm{H}}=7.4 \mathrm{~Hz}\right), 2.21\left(3 \mathrm{H}, \mathrm{s}, \mathrm{CH}_{3}-(\mathrm{Ar}) \mathrm{C}-\mathrm{CH}-\mathrm{CH}-\mathrm{C}\right), 1.07-1.15$ $\left(12 \mathrm{H}, \mathrm{m}, 2 \times\left(\mathrm{CH}_{2}=\mathrm{C}\right)-\mathrm{CH}_{2}-\mathrm{CH}_{3},(\mathrm{Ar}) \mathrm{C}-\mathrm{CH}-\mathrm{CH}-\mathrm{C}-\mathrm{CH}\left(\mathrm{CH}_{3}\right)_{2}\right)$; ${ }^{13} \mathrm{C}$ NMR $\left(\mathrm{CDCl}_{3}\right) \delta_{\mathrm{C}}(\mathrm{ppm}) 195.8(2 \mathrm{C}, 2 \times(\mathrm{Ar}) \mathrm{C}-(\mathrm{C}=\mathrm{O})-(\mathrm{C}=$ 
$\left.\left.\mathrm{CH}_{2}\right)\right), 168.3\left(2 \mathrm{C}, 2 \times(\mathrm{Ar}) \mathrm{C}-\mathrm{O}-\mathrm{CH}_{2}-(\mathrm{C}=\mathrm{O})\right), 162.3(2 \mathrm{C}, 2 \times$ (Py)N-CH-C-(C=O)-O), $157.1 \quad(2 \mathrm{C}, 2 \times(\mathrm{Py}) \mathrm{N}-\mathrm{C}-\mathrm{CH}-\mathrm{CH}-\mathrm{C})$, $156.1(2 \mathrm{C}, 2 \times(\mathrm{Py}) \mathrm{N}-\mathrm{CH}-\mathrm{C}-(\mathrm{C}=\mathrm{O})), 155.3(2 \mathrm{C}, 2 \times(\mathrm{Ar}) \mathrm{CH}-\mathrm{C}-$ O), $150.2\left(2 \mathrm{C}, 2 \times \mathrm{CH}_{3}-\mathrm{CH}_{2}-\left(\mathrm{C}=\mathrm{CH}_{2}\right)\right), 140.8(2 \mathrm{C}, 2 \times(\mathrm{Py}) \mathrm{N}-\mathrm{C}-$ $\mathrm{CH}-\mathrm{CH}-\mathrm{C}), 134.0(2 \mathrm{C}, 2 \times \mathrm{Cl}-(\mathrm{Ar}) \mathrm{C}-\mathrm{C}-(\mathrm{C}=\mathrm{O})), 131.4(2 \mathrm{C}, 2 \times$ $\mathrm{Cl}-(\mathrm{Ar}) \mathrm{C}-\mathrm{C}-(\mathrm{C}=\mathrm{O})), 129.5(2 \mathrm{C}, 2 \times(\mathrm{Ar}) \mathrm{CH}-\mathrm{C}-(\mathrm{C}=\mathrm{O})), 129.0$ $\left(2 \mathrm{C}, 2 \times\left(\mathrm{CH}_{2}=\mathrm{C}\right)-\mathrm{CH}_{2}-\mathrm{CH}_{3}\right), 127.1(2 \mathrm{C}, 2 \times(\mathrm{Py}) \mathrm{N}-\mathrm{C}-\mathrm{CH}-\mathrm{CH}-\mathrm{C})$, $126.6(2 \mathrm{C}, 2 \times(\mathrm{Py}) \mathrm{N}-\mathrm{CH}-\mathrm{C}-(\mathrm{C}=\mathrm{O})-\mathrm{O}), 123.2(2 \mathrm{C}, 2 \times \mathrm{Cl}-(\mathrm{Ar}) \mathrm{C}-$ $\mathrm{C}-\mathrm{O}), 111.3\left(2 \mathrm{C}, 2 \times(\mathrm{Ar}) \mathrm{CH}-\mathrm{C}-\mathrm{O}-\mathrm{CH}_{2}-(\mathrm{C}=\mathrm{O})\right), 106.3\left(1 \mathrm{C}, \mathrm{CH}_{3}-\right.$ (Ar)C-CH-CH-C), 103.5 (1C, $\left.\mathrm{CH}_{3}-(\mathrm{Ar}) \mathrm{C}-\mathrm{CH}-\mathrm{CH}-\mathrm{C}\right), 87.2$ (2C, $2 \times$ $\mathrm{CH}_{3}$-(Ar)C-CH-CH-C), 85.1 (2C, $\left.2 \times \mathrm{CH}_{3}-(\mathrm{Ar}) \mathrm{C}-\mathrm{CH}-\mathrm{CH}-\mathrm{C}\right), 66.5$ $\left(2 \mathrm{C}, 2 \times(\mathrm{Ar}) \mathrm{C}-\mathrm{O}-\mathrm{CH}_{2}-(\mathrm{C}=\mathrm{O})\right), 64.7\left(2 \mathrm{C}, 2 \times(\mathrm{Ar}) \mathrm{C}-\mathrm{O}-\mathrm{CH}_{2}-(\mathrm{C}=\right.$ $\left.\mathrm{O})-\mathrm{O}-\mathrm{CH}_{2}-\mathrm{CH}_{2}\right), 62.8\left(2 \mathrm{C}, 2 \times(\mathrm{Ar}) \mathrm{C}-\mathrm{O}-\mathrm{CH}_{2}-(\mathrm{C}=\mathrm{O})-\mathrm{O}-\mathrm{CH}_{2}-\right.$ $\left.\mathrm{CH}_{2}\right), 31.4$ (1C, (Ar)CH-CH-C-CH $\left.\left(\mathrm{CH}_{3}\right)_{2}\right), 23.5(2 \mathrm{C}, 2 \times$ $\left.\left(\mathrm{CH}_{2}=\mathrm{C}\right)-\mathrm{CH}_{2}-\mathrm{CH}_{3}\right), 22.3\left(2 \mathrm{C},(\mathrm{Ar}) \mathrm{CH}-\mathrm{CH}-\mathrm{C}-\mathrm{CH}\left(\mathrm{CH}_{3}\right)_{2}\right), 18.9$ (1C, $\left.\mathrm{CH}_{3}-(\mathrm{Ar}) \mathrm{C}-\mathrm{CH}-\mathrm{CH}-\mathrm{C}\right), 12.5\left(2 \mathrm{C}, 2 \times\left(\mathrm{CH}_{2}=\mathrm{C}\right)-\mathrm{CH}_{2}-\mathrm{CH}_{3}\right)$; IR $\left(\nu, \mathrm{cm}^{-1}\right) 2966\left(\mathrm{C}-\mathrm{H}, \mathrm{CH}_{2}, \mathrm{CH}_{3}\right), 1731(\mathrm{C}=\mathrm{O}$, ester $), 1661$ $(\mathrm{C}=\mathrm{O}$, ketone, $\mathrm{C}=\mathrm{C}$, alkene), 1582, 1468, 1382 (ring skeleton $\mathrm{C}=$ $\mathrm{C}, \mathrm{C}-\mathrm{C}, \mathrm{C}=\mathrm{N}, \mathrm{C}-\mathrm{N}), 1286,1194,1119,1077$ (C-O, ester, ether), 804 (C-H aromatic); ESI-MS $(+) \mathrm{m} / z 1173.08[\mathrm{M}-\mathrm{Cl}]^{+}$, calcd for $\mathrm{C}_{52} \mathrm{H}_{50} \mathrm{Cl}_{5} \mathrm{~N}_{2} \mathrm{O}_{12} \mathrm{Ru}^{+} 1173.29$ (the isotopic pattern corresponds well to the calculated pattern). Anal. Calcd for $\mathrm{C}_{52} \mathrm{H}_{50} \mathrm{Cl}_{6} \mathrm{~N}_{2} \mathrm{O}_{12} \mathrm{Ru}$ : C, 51.67; H, 4.17; N, 2.32. Found: C, 51.71; H, 4.19; N, 2.23.

Synthesis of $\left[\mathrm{Os}\left(\eta^{6}-p\right.\right.$-cymene)CI][bis(2-(2-(2,3-dichloro-4-(2methylenebutanoyl)phenoxy)acetoxy)ethyl)-(2,2'-bipyridine)-5, $5^{\prime}$ dicarboxylate $\mathrm{Cl}(\mathbf{2 b})$. Complex $\mathbf{2 b}$ was prepared following the general procedure starting from $\left[\mathrm{Os}\left(\eta^{6}-p\right.\right.$-cymene $) \mathrm{Cl}_{2} \mathrm{Cl}_{2}(0.110 \mathrm{~g}, 1$ equiv) and ligand $\mathbf{L 2}(0.250 \mathrm{~g}, 2$ equiv), to afford an orange-red solid $\left(0.332\right.$ g, yield 93\%): mp $\left({ }^{\circ} \mathrm{C}\right) 89-91 ;{ }^{1} \mathrm{H}$ NMR $\left(\mathrm{CDCl}_{3}\right) \delta_{\mathrm{H}}(\mathrm{ppm})$ $9.65(2 \mathrm{H}, \mathrm{s}, 2 \times \mathrm{O}-(\mathrm{C}=\mathrm{O})-(\mathrm{Py}) \mathrm{C}-\mathrm{CH}-\mathrm{N}), 9.55(2 \mathrm{H}, \mathrm{d}, 2 \times(\mathrm{Py}) \mathrm{N}-$ $\left.\mathrm{C}-\mathrm{CH}-\mathrm{CH}-\mathrm{C},{ }^{3} J_{\mathrm{H}, \mathrm{H}}=5.2 \mathrm{~Hz}\right), 8.61(2 \mathrm{H}, \mathrm{d}, 2 \times(\mathrm{Py}) \mathrm{N}-\mathrm{C}-\mathrm{CH}-\mathrm{CH}-\mathrm{C}$, $\left.{ }^{3} J_{\mathrm{H}, \mathrm{H}}=5.2 \mathrm{~Hz}\right), 7.11\left(2 \mathrm{H}, \mathrm{d}, 2 \times(\mathrm{Ar}) \mathrm{CH}-\mathrm{C}-(\mathrm{C}=\mathrm{O}),{ }^{3} J_{\mathrm{H}, \mathrm{H}}=8.1 \mathrm{~Hz}\right)$, $6.91\left(2 \mathrm{H}, \mathrm{d}, 2 \times(\mathrm{Ar}) \mathrm{CH}-\mathrm{C}-\mathrm{O}-\mathrm{CH}_{2}-(\mathrm{C}=\mathrm{O}),{ }^{3} \mathrm{~J}_{\mathrm{H}, \mathrm{H}}=8.1 \mathrm{~Hz}\right), 6.28$ $\left(2 \mathrm{H}, \mathrm{m}, 2 \times \mathrm{CH}_{3}-(\mathrm{Ar}) \mathrm{C}-\mathrm{CH}-\mathrm{CH}-\mathrm{C}\right), 6.10\left(2 \mathrm{H}, \mathrm{m}, 2 \times \mathrm{CH}_{3}-(\mathrm{Ar}) \mathrm{C}-\right.$ $\mathrm{CH}-\mathrm{CH}-\mathrm{C}), 5.91\left(2 \mathrm{H}, \mathrm{s}, 2 \times\right.$ cis $\left.(\mathrm{CH}=\mathrm{C})-\mathrm{CH}_{2}-\mathrm{CH}_{3}\right), 5.55(2 \mathrm{H}, \mathrm{s}, 2$ $\times$ trans $\left.(\mathrm{CH}=\mathrm{C})-\mathrm{CH}_{2}-\mathrm{CH}_{3}\right), 4.97(2 \mathrm{H}, \mathrm{d}, 2 \times(\mathrm{Ar}) \mathrm{C}-\mathrm{O}-\mathrm{CH}-(\mathrm{C}=$ $\left.\mathrm{O})-\mathrm{O}-\left(\mathrm{CH}_{2}\right)_{2}-\mathrm{O},{ }^{1} \mathrm{~J}_{\mathrm{H}, \mathrm{H}}=16.4 \mathrm{~Hz}\right), 4.87(2 \mathrm{H}, \mathrm{d}, 2 \times(\mathrm{Ar}) \mathrm{C}-\mathrm{O}-\mathrm{CH}-$ $\left.(\mathrm{C}=\mathrm{O})-\mathrm{O}-\left(\mathrm{CH}_{2}\right)_{2}-\mathrm{O},{ }^{1} J_{\mathrm{H}, \mathrm{H}}=16.4 \mathrm{~Hz}\right), 4.57-4.79(8 \mathrm{H}, \mathrm{m}, 2 \times \mathrm{O}-$ $\left.\mathrm{CH}_{2}-(\mathrm{C}=\mathrm{O})-\mathrm{O}-\mathrm{CH}_{2}-\mathrm{CH}_{2}, 2 \times \mathrm{O}-\mathrm{CH}_{2}-(\mathrm{C}=\mathrm{O})-\mathrm{O}-\mathrm{CH}_{2}-\mathrm{CH}_{2}\right), 2.60$ $\left(1 \mathrm{H}\right.$, sept, $\left.(\mathrm{Ar}) \mathrm{C}-\mathrm{CH}-\mathrm{CH}-\mathrm{C}-\mathrm{CH}\left(\mathrm{CH}_{3}\right)_{2},{ }^{3} \mathrm{~J}_{\mathrm{H}, \mathrm{H}}=6.2 \mathrm{~Hz}\right), 2.41(4 \mathrm{H}, \mathrm{m}$, $\left.2 \times\left(\mathrm{CH}_{2}=\mathrm{C}\right)-\mathrm{CH}_{2}-\mathrm{CH}_{3},{ }^{3} \mathrm{~J}_{\mathrm{H}, \mathrm{H}}=7.4 \mathrm{~Hz}\right), 2.27\left(3 \mathrm{H}, \mathrm{s}, \mathrm{CH}_{3}-(\mathrm{Ar}) \mathrm{C}-\right.$ $\mathrm{CH}-\mathrm{CH}-\mathrm{C}), 1.10\left(6 \mathrm{H}, \mathrm{t}, 2 \times\left(\mathrm{CH}_{2}=\mathrm{C}\right)-\mathrm{CH}_{2}-\mathrm{CH}_{3}\right), 1.03(6 \mathrm{H}, \mathrm{d}$, ( $\left.\mathrm{Ar}) \mathrm{C}-\mathrm{CH}-\mathrm{CH}-\mathrm{C}-\mathrm{CH}\left(\mathrm{CH}_{3}\right)_{2}\right) ;{ }^{13} \mathrm{C}$ NMR $\left(\mathrm{CDCl}_{3}\right) \delta_{\mathrm{C}}(\mathrm{ppm}) 195.8$ $\left(2 \mathrm{C}, 2 \times(\mathrm{Ar}) \mathrm{C}-(\mathrm{C}=\mathrm{O})-\left(\mathrm{C}=\mathrm{CH}_{2}\right)\right), 168.2\left(2 \mathrm{C}, 2 \times(\mathrm{Ar}) \mathrm{C}-\mathrm{O}-\mathrm{CH}_{2}-\right.$ $(\mathrm{C}=\mathrm{O})), 162.1(2 \mathrm{C}, 2 \times(\mathrm{Py}) \mathrm{N}-\mathrm{CH}-\mathrm{C}-(\mathrm{C}=\mathrm{O})-\mathrm{O}), 158.0(2 \mathrm{C}, 2 \times$ (Py)N-C-CH-CH-C), $155.9(2 \mathrm{C}, 2 \times(\mathrm{Py}) \mathrm{N}-\mathrm{CH}-\mathrm{C}-(\mathrm{C}=\mathrm{O})), 155.3$ (2C, $2 \times(\mathrm{Ar})-\mathrm{CH}-\mathrm{C}-\mathrm{O}), 150.1\left(2 \mathrm{C}, 2 \mathrm{xCH}_{3}-\mathrm{CH}_{2}-\left(\mathrm{C}=\mathrm{CH}_{2}\right)\right), 140.9$ $(2 \mathrm{C}, 2 \times(\mathrm{Py}) \mathrm{N}-\mathrm{C}-\mathrm{CH}-\mathrm{CH}-\mathrm{C}), 133.9(2 \mathrm{C}, 2 \times \mathrm{Cl}-(\mathrm{Ar})-\mathrm{C}-\mathrm{C}-(\mathrm{C}=$ O)), $131.3(2 \mathrm{C}, 2 \times \mathrm{Cl}-(\mathrm{Ar})-\mathrm{C}-\mathrm{C}-(\mathrm{C}=\mathrm{O})), 130.1(2 \mathrm{C}, 2 \times(\mathrm{Ar})-$ $\mathrm{CH}-\mathrm{C}-(\mathrm{C}=\mathrm{O})), 129.1\left(2 \mathrm{C}, 2 \times\left(\mathrm{CH}_{2}=\mathrm{C}\right)-\mathrm{CH}_{2}-\mathrm{CH}_{3}\right), 127.1(2 \mathrm{C}, 2$ $\times(\mathrm{Py}) \mathrm{N}-\mathrm{C}-\mathrm{CH}-\mathrm{CH}-\mathrm{C}), 126.9(2 \mathrm{C}, 2 \times(\mathrm{Py}) \mathrm{N}-\mathrm{CH}-\mathrm{C}-(\mathrm{C}=\mathrm{O})-\mathrm{O})$, $123.1(2 \mathrm{C}, 2 \times \mathrm{Cl}-(\mathrm{Ar}) \mathrm{C}-\mathrm{C}-\mathrm{O}), 111.3\left(2 \mathrm{C}, 2 \times(\mathrm{Ar}) \mathrm{CH}-\mathrm{C}-\mathrm{O}-\mathrm{CH}_{2}-\right.$ $(\mathrm{C}=\mathrm{O})$ ), 97.2 (1C, $\left.\mathrm{CH}_{3}-(\mathrm{Ar}) \mathrm{C}-\mathrm{CH}-\mathrm{CH}-\mathrm{C}\right), 96.9$ (1C, $\mathrm{CH}_{3}-(\mathrm{Ar}) \mathrm{C}-$ CH-CH-C), 78.9 (2C, $\left.2 \times \mathrm{CH}_{3}-(\mathrm{Ar}) \mathrm{C}-\mathrm{CH}-\mathrm{CH}-\mathrm{C}\right), 75.4(2 \mathrm{C}, 2 \times$ $\left.\mathrm{CH}_{3}-(\mathrm{Ar}) \mathrm{C}-\mathrm{CH}-\mathrm{CH}-\mathrm{C}\right), 66.4\left(2 \mathrm{C}, 2 \times(\mathrm{Ar}) \mathrm{C}-\mathrm{O}-\mathrm{CH}_{2}-(\mathrm{C}=\mathrm{O})\right), 64.7$ $\left(2 \mathrm{C}, 2 \times(\mathrm{Ar}) \mathrm{C}-\mathrm{O}-\mathrm{CH}_{2}-(\mathrm{C}=\mathrm{O})-\mathrm{O}-\mathrm{CH}_{2}-\mathrm{CH}_{2}\right), 62.8(2 \mathrm{C}, 2 \times(\mathrm{Ar}) \mathrm{C}-$ $\left.\mathrm{O}-\mathrm{CH}_{2}-(\mathrm{C}=\mathrm{O})-\mathrm{O}-\mathrm{CH}_{2}-\mathrm{CH}_{2}\right), 31.4\left(1 \mathrm{C},(\mathrm{Ar}) \mathrm{CH}-\mathrm{CH}-\mathrm{C}-\mathrm{CH}\left(\mathrm{CH}_{3}\right)_{2}\right)$, $23.4\left(2 \mathrm{C}, 2 \times\left(\mathrm{CH}_{2}=\mathrm{C}\right)-\mathrm{CH}_{2}-\mathrm{CH}_{3}\right), 22.5(2 \mathrm{C},(\mathrm{Ar}) \mathrm{CH}-\mathrm{CH}-\mathrm{C}-$ $\left.\mathrm{CH}\left(\mathrm{CH}_{3}\right)_{2}\right), 18.8$ (1C, $\left.\mathrm{CH}_{3}-(\mathrm{Ar}) \mathrm{C}-\mathrm{CH}-\mathrm{CH}-\mathrm{C}\right), 12.4(2 \mathrm{C}, 2 \times$ $\left.\left(\mathrm{CH}_{2}=\mathrm{C}\right)-\mathrm{CH}_{2}-\mathrm{CH}_{3}\right)$; IR $\left(\nu, \mathrm{cm}^{-1}\right) 2967\left(\mathrm{C}-\mathrm{H}, \mathrm{CH}_{2}, \mathrm{CH}_{3}\right), 1731$ $(\mathrm{C}=\mathrm{O}$, ester $), 1662(\mathrm{C}=\mathrm{O}$, ketone, $\mathrm{C}=\mathrm{C}$, alkene $), 1583,1469$, 1382 (ring skeleton $\mathrm{C}=\mathrm{C}, \mathrm{C}-\mathrm{C}, \mathrm{C}=\mathrm{N}, \mathrm{C}-\mathrm{N}$ ), 1287, 1195, 1120, 1078 (C-O, ester, ether), 805 (C-H aromatic); ESI-MS(+) $\mathrm{m} / z$ $1262.14[\mathrm{M}-\mathrm{Cl}]^{+}$, calcd for $\mathrm{C}_{52} \mathrm{H}_{50} \mathrm{Cl}_{5} \mathrm{~N}_{2} \mathrm{O}_{12} \mathrm{Os}^{+} 1262.45$ (the isotopic pattern corresponds well to the calculated pattern). Anal. Calcd for $\mathrm{C}_{52} \mathrm{H}_{50} \mathrm{Cl}_{6} \mathrm{~N}_{2} \mathrm{O}_{12} \mathrm{Os}$ : C, 48.12; H, 3.88, N, 2.16. Found: C, 48.13; H, 3.92; N, 2.06.

X-ray Structure Determination for $\mathbf{1 b}$. Diffraction data were recorded at low temperature $(100(2) \mathrm{K})$ using $\mathrm{Mo} \mathrm{K} \alpha$ radiation on a
Bruker APEX II CCD diffractometer equipped with a $\kappa$ geometry goniometer.

The data sets were reduced by EvalCCD ${ }^{77}$ and then corrected for absorption. $^{78}$ The solution and refinement were performed by SHELXT and SHELXL2014 (release 7). ${ }^{79}$ The crystal structures were refined using full-matrix least squares based on $F^{2}$ with all nonhydrogen atoms anisotropically defined. Hydrogen atoms were placed in calculated positions by means of the "riding" model. Additional electron density found in the difference Fourier map of the compound (due to disordered solvent) was treated by the SQUEEZE algorithm of PLATON $^{80}$ and then treated by the ABIN instruction in SHELXL2014. Crystal data and structure refinement details are given in Table 3.

Table 3. Crystal Data and Structure Refinement Details for $1 \mathrm{~b}$

\begin{tabular}{|c|c|}
\hline chem formula & $\mathrm{C}_{35} \mathrm{H}_{36} \mathrm{Cl}_{4} \mathrm{~N}_{2} \mathrm{O}_{4} \mathrm{Os} \cdot \mathrm{CHCl}_{3} \cdot \mathrm{CH}_{3} \mathrm{OH}$ \\
\hline formula wt & 1032.07 \\
\hline temp $(\mathrm{K})$ & $100(2)$ \\
\hline wavelength $(\AA)$ & 0.71073 \\
\hline cryst syst & triclinic \\
\hline space group & $P \overline{1}$ \\
\hline \multicolumn{2}{|l|}{ unit cell dimens } \\
\hline$a(\AA)$ & $11.7589(16)$ \\
\hline$b(\AA)$ & $12.2253(7)$ \\
\hline$c(\AA)$ & $16.4565(10)$ \\
\hline$\alpha(\operatorname{deg})$ & $70.951(7)$ \\
\hline$\beta(\operatorname{deg})$ & $79.147(8)$ \\
\hline$\gamma(\mathrm{deg})$ & $75.472(6)$ \\
\hline$V\left(\AA^{3}\right)$ & $2150.0(4)$ \\
\hline Z & 2 \\
\hline$D_{\text {calcd }}\left(\mathrm{g} / \mathrm{cm}^{3}\right)$ & 1.594 \\
\hline$\mu\left(\mathrm{mm}^{-1}\right)$ & 3.442 \\
\hline$F(000)$ & 1024 \\
\hline cryst size (mm) & $0.319 \times 0.212 \times 0.102$ \\
\hline$\theta$ range for data collection ( $\mathrm{deg}$ ) & $1.893-27.498$ \\
\hline \multicolumn{2}{|l|}{ index ranges } \\
\hline$h$ & -15 to +15 \\
\hline$k$ & -15 to +15 \\
\hline$l$ & -21 to +21 \\
\hline no. of measd rflns & 27952 \\
\hline no. of indep rflns & $9668(R($ int $)=0.0690)$ \\
\hline completeness to $\theta=25.242^{\circ}(\%)$ & 99.2 \\
\hline abs cor & semiempirical from equivalents \\
\hline max and min transmission & 0.7456 and 0.3830 \\
\hline refinement method & full-matrix least squares on $F^{2}$ \\
\hline no. of data/restraints/params & $9668 / 187 / 543$ \\
\hline GOF & 1.052 \\
\hline $\mathrm{R} 1(I>2 \sigma(I))$ & 0.0696 \\
\hline wR2 $(I>2 \sigma(I))$ & 0.1595 \\
\hline R1 (all data) & 0.0996 \\
\hline wR2 (all data) & 0.1808 \\
\hline largest diff peak and hole $\left(\mathrm{e} \AA^{-3}\right)$ & 2.802 and -1.706 \\
\hline
\end{tabular}

Protein Expression and Purification. Human GST P1-1 wildtype was expressed in Escherichia coli and purified as previously described. ${ }^{66}$ The reaction was monitored by spectrophotometry at 340 $\mathrm{nm}$, corresponding to the absorbance maximum of glutathione-2,4dinitrobenzene conjugate $\left(\varepsilon_{340}=9.6 \mathrm{M}^{-1} \mathrm{~cm}^{-1}\right) .81$ Spectrophotometric measurements were performed using a double-beam Cary UVvis 4000 spectrophotometer (Kontron Instruments) equipped with a thermostated cuvette compartment.

GST P1-1 Inhibition Assay. The residual enzymatic activity of GST P1-1 was assayed by spectrophotometry in $100 \mathrm{mM}$ phosphate buffer, $\mathrm{pH} 6.5$, in the presence of variable amounts of compound 1a, 
$\mathbf{1 b}, \mathbf{2 a}$, or $\mathbf{2 b}$ (from 1 to $100 \mu \mathrm{M}$ ), predissolved in DMSO, $1 \mathrm{mM} \mathrm{GSH}$ (glutathione), and $1 \mathrm{mM} \mathrm{CDNB}$ (1-chloro-2,4-dinitrobenzene), at 25 ${ }^{\circ} \mathrm{C}$. The $\mathrm{IC}_{50}$ values for the inhibition of GST P1-1 were determined by fitting a plot of residual GST activity against the inhibitor concentrations with a sigmoidal dose-response function using Graph PAD Prism (Graph PAD Software, San Diego, CA).

Cell Culture. Human A2780 and A2780cisR ovarian carcinoma cells were obtained from the European Centre of Cell Cultures (ECACC, U.K.). The resistance of the A2780cisR cells was maintained by a monthly treatment with cisplatin $(2 \mu \mathrm{M}$ /one 4 day passage $)$. Nontumorigenic HEK-293 cells were provided by the Institute of Pathology, CHUV, Lausanne, Switzerland. A2780 and A2780cisR were grown in RPMI 1640 medium supplemented with GlutaMAX (Gibco), and HEK-293 cells were grown in DMEM medium, all containing heat-inactivated fetal calf serum (FCS, Sigma, USA) (10\%) and antibiotics (penicillin $(100 \mathrm{U} / \mathrm{mL})$ :streptomycin $(100 \mu \mathrm{g} / \mathrm{mL})$, working concentration 1:100, Life Technologies, Gibco) at $37^{\circ} \mathrm{C}$ and $\mathrm{CO}_{2}(5 \%)$.

Antiproliferative Activity in Vitro. Cytotoxicity was determined using the MTT assay (MTT = 3-(4,5-dimethyl-2-thiazolyl)-2,5diphenyl-2H-tetrazolium bromide). Cells were seeded in 96-well plates as monolayers with $100 \mu \mathrm{L}$ of cell solution per well and preincubated for $24 \mathrm{~h}$ in the cell medium. Compounds were prepared as DMSO solutions that were rapidly dissolved in the culture medium and serially diluted to the appropriate concentration to give a final DMSO concentration of $0.5 \%$. A $100 \mu \mathrm{L}$ portion of the drug solution was added to each well, and the plates were incubated for another 72 h. Subsequently, MTT ( $5 \mathrm{mg} / \mathrm{mL}$ solution) was added to the cells and the plates were incubated for a further $4 \mathrm{~h}$. The culture medium was aspirated, and the purple formazan crystals formed by the mitochondrial dehydrogenase activity of vital cells were dissolved in DMSO. The optical density, directly proportional to the number of surviving cells, was quantified at $540 \mathrm{~nm}$ using a multiwell plate reader, and the fraction of surviving cells was calculated from the absorbance of untreated control cells. Evaluation was based on means from two independent experiments, each comprising three microcultures per concentration level.

\section{ASSOCIATED CONTENT}

\section{S Supporting Information}

The Supporting Information is available free of charge on the ACS Publications website at DOI: 10.1021/acs.organomet.7b00468.

Packing diagrams of the crystal structure and relevant bond parameters, stability data for the complexes in DMSO- $d_{6}$, and GST P1-1 inhibition curves (PDF)

\section{Accession Codes}

CCDC 1555830 contains the supplementary crystallographic data for this paper. These data can be obtained free of charge via www.ccdc.cam.ac.uk/data_request/cif, or by emailing data request@ccdc.cam.ac.uk, or by contacting The Cambridge Crystallographic Data Centre, 12 Union Road, Cambridge CB2 1EZ, UK; fax: +44 1223336033.

\section{AUTHOR INFORMATION}

\section{Corresponding Authors}

*E.P.: e-mail, paunescu_emilia@yahoo.com.

*P.J.D.: tel, +41-21-6939854; fax, +41-21-6939853; e-mail, paul.dyson@epfl.ch.

\section{ORCID ${ }^{\circ}$}

Paul J. Dyson: 0000-0003-3117-3249

Notes

The authors declare no competing financial interest.

${ }^{\perp}$ Deceased.

\section{ACKNOWLEDGMENTS}

We thank the Swiss National Science Foundation (200020157107) and EPFL for financial support and Dr. Euro Solari (EPFL) for the elemental analysis and assistance with the crystal structure determination.

\section{REFERENCES}

(1) Perez, R. P.; Hamilton, T. C.; Ozols, R. F.; Young, R. C. Cancer 1993, 71, 1571-1580.

(2) Townsend, D. M.; Tew, K. D. Oncogene 2003, 22, 7369-7375.

(3) Tew, K. D. Cancer Res. 1994, 54, 4313-4320.

(4) Sau, A.; Tregno, F. P.; Valentino, F.; Federici, G.; Caccuri, A. M. Arch. Biochem. Biophys. 2010, 500, 116-122.

(5) Townsend, D. M.; Tew, K. D. Am. J. PharmacoGenomics 2003, 3, $157-172$.

(6) Morrow, C. S.; Cowan, K. H. Cancer cells 1990, 2, 15-22.

(7) Kalinina, E. V.; Chernov, N. N.; Saprin, A. N.; Kotova, Y. N.; Remizov, V. I.; Shcherbak, N. P. B. Bull. Exp. Biol. Med. 2007, 143, 328-330.

(8) Beaumont, P. O.; Moore, M. J.; Ahmad, K.; Payne, M. M.; Lee, C. J.; Riddick, D. S. Cancer Res. 1998, 58, 947-955.

(9) Godwin, A. K.; Meister, A.; Huang, C. S.; Hamilton, T. C.; Anderson, M. E. P. Proc. Natl. Acad. Sci. U. S. A. 1992, 89, 3070-3074.

(10) Sawers, L.; Ferguson, M. J.; Ihrig, B. R.; Young, H. C.; Chakravarty, P.; Wolf, C. R.; Smith, G. Br. J. Cancer 2014, 111, 11501158.

(11) Yan, X. D.; Pan, L. Y.; Yuan, Y.; Lang, J. H.; Mao, N. J. Proteome Res. 2007, 6, 772-780.

(12) Piaggi, S.; Raggi, C.; Corti, A.; Pitzalis, E.; Mascherpa, M. C.; Saviozzi, M.; Pompella, A.; Casini, A. F. Carcinogenesis 2010, 31, 804811.

(13) Pasello, M.; Michelacci, F.; Scionti, I.; Hattinger, C. M.; Zuntini, M.; Caccuri, A. M.; Scotlandi, K.; Picci, P.; Serra, M. Cancer Res. 2008, 68, 6661-6668.

(14) Kase, H.; Kodama, S.; Tanaka, K. Int. J. Gynecol. Cancer 1996, 6, 241-245.

(15) Cullen, K. J.; Newkirk, K. A.; Schumaker, L. M.; Aldosari, N.; Rone, J. D.; Haddad, B. R. Cancer Res. 2003, 63, 8097-8102.

(16) Ruzza, P.; Calderan, A. Pharmaceutics 2013, 5, 220-231.

(17) Ramsay, E. E.; Dilda, P. J.; Front. Pharmacol. 2014, 5, 181.

(18) Ruzza, P.; Rosato, A.; Rossi, C. R.; Floreani, M.; Quintieri, L. Anti-Cancer Agents Med. Chem. 2009, 9, 763-777.

(19) Schultz, M.; Dutta, S.; Tew, K. D. Adv. Drug Delivery Rev. 1997, 26, 91-104.

(20) Rhodes, T.; Twentyman, P. R. Br. J. Cancer 1992, 65, 684-690.

(21) Hansson, J.; Berhane, K.; Castro, V. M.; Jungnelius, U.; Mannervik, B.; Ringborg, U. Cancer Res. 1991, 51, 94-98.

(22) Caffrey, P. B.; Zhu, M.; Zhang, Y.; Chinen, N.; Frenkel, G. D. Cancer Lett. 1999, 136, 47-52.

(23) Clapper, M. L.; Hoffman, S. J.; Tew, K. D. J. Cell. Pharmacol. 1990, 1, 71-78.

(24) Evans, C. G.; Bodell, W. J.; Tokuda, K.; Doane-Setzer, P.; Smith, M. T. Cancer Res. 1987, 47, 2525-2530.

(25) Xu, B. H.; Singh, S. V. Cancer Res. 1992, 52, 6666-6670.

(26) Nagourney, R. A.; Messenger, J. C.; Kern, D. H.; Weisenthal, L. M. Cancer Chemother. Pharmacol. 1990, 26, 318-322.

(27) Tew, K. D.; Bomber, A. M.; Hoffman, S. J. Cancer Res. 1988, 48, $3622-3625$.

(28) Awasthi, S.; Singhal, S. S.; He, N. G.; Chaubey, M.; Zimniak, P.; Srivastava, S. K.; Singh, S. V.; Awasthi, Y. C. Int. J. Cancer 1996, 68, 333-339.

(29) Zhang, K.; Chew, M.; Yang, E. B.; Wong, K. P.; Mack, P. Mol. Pharmacol. 2001, 59, 837-843.

(30) Ding, D.; Jiang, H.; Wang, P.; Salvi, R. Hear. Res. 2007, 226, $129-139$.

(31) Zaman, G. J.; Cnubben, N. H.; van Bladeren, P. J.; Evers, R.; Borst, P. FEBS Lett. 1996, 391, 126-130. 
(32) Yang, Q.; Xiao, H. H.; Cai, J.; Xie, Z. G.; Wang, Z. H.; Jing, X. B. RSC Adv. 2014, 4, 61124-61132.

(33) Ang, W. H.; Parker, L. J.; De Luca, A.; Juillerat-Jeanneret, L.; Morton, C. J.; Lo Bello, M.; Parker, M. W.; Dyson, P. J. Angew. Chem., Int. Ed. 2009, 48, 3854-3857.

(34) Zanellato, I.; Bonarrigo, I.; Sardi, M.; Alessio, M.; Gabano, E.; Ravera, M.; Osella, D. ChemMedChem 2011, 6, 2287-2293.

(35) Parker, L. J.; Italiano, L. C.; Morton, C. J.; Hancock, N. C.; Ascher, D. B.; Aitken, J. B.; Harris, H. H.; Campomanes, P.; Rothlisberger, U.; De Luca, A.; Lo Bello, M.; Ang, W. H.; Dyson, P. J.; Parker, M. W. Chem. - Eur. J. 2011, 17, 7806-7816.

(36) Johansson, K.; Ito, M.; Schophuizen, C. M.; Mathew Thengumtharayil, S.; Heuser, V. D.; Zhang, J.; Shimoji, M.; Vahter, M.; Ang, W. H.; Dyson, P. J.; Shibata, A.; Shuto, S.; Ito, Y.; Abe, H.; Morgenstern, R. Mol. Pharmaceutics 2011, 8, 1698-1708.

(37) Rademaker-Lakhai, J. M.; van den Bongard, D.; Pluim, D.; Beijnen, J. H.; Schellens, J. H. M. Clin. Cancer Res. 2004, 10, 37173727.

(38) Leijen, S.; Burgers, S. A.; Baas, P.; Pluim, D.; Tibben, M.; van Werkhoven, E.; Alessio, E.; Sava, G.; Beijnen, J. H.; Schellens, J. H. M. Invest. New Drugs 2015, 33, 201-214.

(39) Bergamo, A.; Sava, G. Chem. Soc. Rev. 2015, 44, 8818-8835.

(40) Hartinger, C. G.; Jakupec, M. A.; Zorbas-Seifried, S.; Groessl, M.; Egger, A.; Berger, W.; Zorbas, H.; Dyson, P. J.; Keppler, B. K. Chem. Biodiversity 2008, 5, 2140-2155.

(41) Trondl, R.; Heffeter, P.; Kowol, C. R.; Jakupec, M. A.; Berger, W.; Keppler, B. K. Chem. Sci. 2014, 5, 2925-2932.

(42) Bergamo, A.; Masi, A.; Dyson, P. J.; Sava, G. Int. J. Oncol. 2008, 33, 1281-1289.

(43) Weiss, A.; Berndsen, R. H.; Dubois, M.; Muller, C.; Schibli, R.; Griffioen, A. W.; Dyson, P. J. Nowak-Sliwinska, P. Chem. Sci. 2014, 5, $4742-4748$.

(44) Scolaro, C.; Bergamo, A.; Brescacin, L.; Delfino, R.; Cocchietto, M.; Laurenczy, G.; Geldbach, T. J.; Sava, G.; Dyson, P. J. J. Med. Chem. 2005, 48, 4161-4171.

(45) Nowak-Sliwinska, P.; van Beijnum, J. R.; Casini, A.; Nazarov, A. A.; Wagnieres, G.; van den Bergh, H.; Dyson, P. J.; Griffioen, A. W. J. J. Med. Chem. 2011, 54, 3895-3902.

(46) Aird, R. E.; Cummings, J.; Ritchie, A. A.; Muir, M.; Morris, R. E.; Chen, H.; Sadler, P. J.; Jodrell, D. I. Br. J. Cancer 2002, 86, 1652-1657.

(47) Morris, R. E.; Aird, R. E.; Murdoch, P. D.; Chen, H. M.; Cummings, J.; Hughes, N. D.; Parsons, S.; Parkin, A.; Boyd, G.; Jodrell, D. I.; Sadler, P. J. J. J. Med. Chem. 2001, 44, 3616-3621.

(48) Bergamo, A.; Masi, A.; Peacock, A. F.; Habtemariam, A.; Sadler, P. J.; Sava, G. J. J. Inorg. Biochem. 2010, 104, 79-86.

(49) Casini, A.; Edafe, F.; Erlandsson, M.; Gonsalvi, L.; Ciancetta, A.; Re, N.; Ienco, A.; Messori, L.; Peruzzini, M.; Dyson, P. J. Dalton Trans. 2010, 39, 5556-5563.

(50) Arion, V. B.; Dobrov, A.; Goschl, S.; Jakupec, M. A.; Keppler, B. K.; Rapta, P. Chem. Commun. 2012, 48, 8559-8561.

(51) Kandioller, W.; Balsano, E.; Meier, S. M.; Jungwirth, U.; Goschl, S.; Roller, A.; Jakupec, M. A.; Berger, W.; Keppler, B. K.; Hartinger, C. G. Chem. Commun. 2013, 49, 3348-3350.

(52) Turel, I.; Kljun, J.; Perdih, F.; Morozova, E.; Bakulev, V.; Kasyanenko, N.; Byl, J. A.; Osheroff, N. Inorg. Chem. 2010, 49, 1075010752.

(53) Nazarov, A. A.; Meier, S. M.; Zava, O.; Nosova, Y. N.; Milaeva, E. R.; Hartinger, C. G.; Dyson, P. J. Dalton Trans. 2015, 44, 36143623.

(54) Nosova, Y. N.; Karlov, D. S.; Pisarev, S. A.; Shutkov, I. A.; Palyulin, V. A.; Baquié, M.; Milaeva, E. R.; Dyson, P. J.; Nazarov, A. A. J. J. Organomet. Chem. 2017, 839, 91-97.

(55) Ashraf, A.; Hanif, M.; Kubanik, M.; Söhnel, T.; Jamieson, S. M. F.; Bhattacharyya, A.; Hartinger, C. G. J. Organomet. Chem. 2017, 839, $31-37$.

(56) Hanif, M.; Meier, S. M.; Adhireksan, Z.; Henke, H.; Martic, S.; Movassaghi, S.; Labib, M.; Kandioller, W.; Jamieson, S. M. F.; Hejl, M.; Jakupec, M. A.; Kraatz, H.-B.; Davey, C. A.; Keppler, B. K.; Hartinger, C. G. ChemPlusChem 2017, 82, 841-847.
(57) Aman, F.; Hanif, M.; Kubanik, M.; Ashraf, A.; Söhnel, T.; Jamieson, S. M. F.; Siddiqui, W. A.; Hartinger, C. G. Chem. - Eur. J. 2017, 23, 4893-4902.

(58) Ang, W. H.; De Luca, A.; Chapuis-Bernasconi, C.; JuilleratJeanneret, L.; Lo Bello, M.; Dyson, P. ChemMedChem 2007, 2, 17991806.

(59) Chatterjee, S.; Biondi, I.; Dyson, P. J.; Bhattacharyya, A. J. JBIC, J. Biol. Inorg. Chem. 2011, 16, 715-724.

(60) Agonigi, G.; Riedel, T.; Zacchini, S.; Paunescu, E.; Pampaloni, G.; Bartalucci, N.; Dyson, P. J.; Marchetti, F. Inorg. Chem. 2015, 54, 6504-6512.

(61) Agonigi, G.; Riedel, T.; Pilar Gay, M.; Biancalana, L.; Onate, E.; Dyson, P. J.; Pampaloni, G.; Paunescu, E.; Esteruelas, M. A.; Marchetti, F. Organometallics 2016, 35, 1046-1056.

(62) Biancalana, L.; Batchelor, L. K.; De Palo, A.; Zacchini, S.; Pampaloni, G.; Dyson, P. J.; Marchetti, F. Dalton Trans. 2017, DOI: 10.1039/C7DT02062G.

(63) Maeda, D. Y.; Mahajan, S. S.; Atkins, W. M.; Zebala, J. A. Bioorg. Med. Chem. Lett. 2006, 16, 3780-3783.

(64) Mahajan, S. S.; Hou, L. M.; Doneanu, C.; Paranji, R.; Maeda, D.; Zebala, J.; Atkins, W. M. J. J. Am. Chem. Soc. 2006, 128, 8615-8625.

(65) Ganter, C. Chem. Soc. Rev. 2003, 32, 130-138.

(66) Battistoni, A.; Mazzetti, A. P.; Petruzzelli, R.; Muramatsu, M.; Federici, G.; Ricci, G.; Lobello, M. Protein Expression Purif. 1995, 6, $579-587$.

(67) Lo Bello, M.; Battistoni, A.; Mazzetti, A. P.; Board, P. G.; Muramatsu, M.; Federici, G.; Ricci, G. J. J. Biol. Chem. 1995, 270, $1249-1253$

(68) Habig, W. H.; Pabst, M. J.; Jakoby, W. B. J. Biol. Chem. 1974, 249, 7130-7139.

(69) Kilpin, K. J.; Clavel, C. M.; Edafe, F.; Dyson, P. J. Organometallics 2012, 31, 7031-7039.

(70) Fu, Y.; Sanchez-Cano, C.; Soni, R.; Romero-Canelon, I.; Hearn, J. M.; Liu, Z.; Wills, M.; Sadler, P. J. Dalton Trans. 2016, 45, 83678378.

(71) Fu, Y.; Soni, R.; Romero, M. J.; Pizarro, A. M.; Salassa, L.; Clarkson, G. J.; Hearn, J. M.; Habtemariam, A.; Wills, M.; Sadler, P. J. Chem. - Eur. J. 2013, 19, 15199-15209.

(72) Kilpin, K. J.; Cammack, S. M.; Clavel, C. M.; Dyson, P. J. Dalton Trans. 2013, 42, 2008-2014.

(73) Murray, B. S.; Menin, L.; Scopelliti, R.; Dyson, P. J. Chem. Sci. 2014, 5, 2536-2545.

(74) Hanif, M.; Babak, M. V.; Hartinger, C. G. Drug Discovery Today 2014, 19, 1640-1648.

(75) Bennett, M. A.; Smith, A. K. J. J. Chem. Soc., Dalton Trans. 1974, 233-241.

(76) Fulmer, G. R.; Miller, A. J. M.; Sherden, N. H.; Gottlieb, H. E.; Nudelman, A.; Stoltz, B. M.; Bercaw, J. E.; Goldberg, K. I. Organometallics 2010, 29, 2176-2179.

(77) Duisenberg, A. J. M.; Kroon-Batenburg, L. M. J.; Schreurs, A. M. M. J. Appl. Crystallogr. 2003, 36, 220-229.

(78) Blessing, R. H. Acta Crystallogr., Sect. A: Found. Crystallogr. 1995, $51,33-38$.

(79) Sheldrick, G. M. Acta Crystallogr., Sect. A: Found. Crystallogr. 2008, 64, 112-122.

(80) Spek, A. L. Acta Crystallogr., Sect. D: Biol. Crystallogr. 2009, 65, $148-155$.

(81) Jakoby, W. B. Methods Enzymol. 1985, 113, 495-499. 